This document is the Accepted Manuscript version of a Published Work that appeared in final form in ACS Catalysis, copyright (C) American Chemical Society after peer review and technical editing by the publisher. To access the final edited and published work see https://pubs.acs.org/doi/10.1021/acscatal.8b04236

\title{
Atomically Thin Metal Films on Foreign Substrates: From Lattice Mismatch to Electrocatalytic Activity
}

\author{
Igor A. Pašti, $*, \dagger, \perp \odot$ Edvin Fako, ${ }^{\ddagger}$ Ana S. Dobrota, ${ }^{\dagger}$ Núria López, ${ }^{\ddagger}$ Natalia V. Skorodumova, ${ }^{\S, \perp}$
} and Slavko V. Mentus ${ }^{\dagger, \#}$

\author{
${ }^{\dagger}$ University of Belgrade, Faculty of Physical Chemistry, Studentski trg 12-16, 11158 Belgrade, Serbia \\ ${ }^{\perp}$ Department of Materials Science and Engineering, School of Industrial Engineering and Management, KTH-Royal Institute of \\ Technology, Brinellvägen 23, 10044 Stockholm, Sweden \\ ${ }^{\ddagger}$ Institute of Chemical Research of Catalonia (ICIQ), The Barcelona Institute of Science and Technology, Tarragona, Spain \\ ${ }^{\S}$ Department of Physics and Astronomy, Uppsala University, Box 516, 75120 Uppsala, Sweden \\ \#Serbian Academy of Sciences and Arts, Knez Mihajlova 35, 11000 Belgrade, Serbia
}

\begin{abstract}
Electrocatalytic properties of materials are governed by the electronic structure, stability, and reactivity of the surface layer which is exposed to the electrolyte. Over the years, different strategies have been developed to tailor electrocatalyst surfaces but also to reduce the cost of these materials, which is the bottleneck for any practical application. When a very thin metallic layer, intended to serve as an electrocatalyst, is placed over a substrate, its configuration is influenced by the structure of the substrate due to lattice mismatch, while the electronic structure is affected due to the strain and the electronic effects of the support. This results in altered bonding within the electrocatalyst layer and the modification of its electronic properties when compared to the


pure phase. In this contribution, we address the possibilities of theoretical prediction of surface properties of atomically thin electrocatalyst films formed over different substrates, focusing on the metal side of the electrified interface. While all these properties can be calculated quite easily using modern computational techniques (but used with care), most often based on density functional theory, we also address an attractive, fast screening possibility to estimate the properties of monometallic and multimetallic overlayers using small sets of calculations on model systems. We discuss how lattice mismatch between a substrate and an overlayer can be used to predict the properties of electrocatalytic films, limitations of such approach, and a possibility of deploying of large databases which enable rapid prescreening of different support/overlayer systems for various electrocatalytic applications.
\end{abstract}

KEYWORDS: thin film, lattice mismatch, strain, metal films, alloy films

\section{INTRODUCTION}

With increasing global energy demands, sustainability cannot be achieved by relying on fossil fuel reserves. This implies the need of harvesting alternative renewable primary energy sources, their storage, and conversion on demand. Electrochemistry, which by colloquial definition deals with interconversion of chemical to electrical energy and vice versa, turned out to be a natural choice to solve this problem. ${ }^{1}$ While most of the electrochemical applications are directed to energy storage applications, it must be stressed that the power of electrons as reactants has been recognized. Electrochemical reactions can be extremely selective, scalable, and easy to control by means of the electrode potential. ${ }^{2}$ Hence, the "electrification" of industrial catalytic processes seems as a natural path in the evolution of the existing catalytic technologies.
Various types of batteries satisfy most of the current energy conversion and storage requirements, but their extensive use leads to a number of problems, caused by the ample mining of scarce, toxic, or critical elements, resulting in growing prices and frequently raised questions of sustainability of such solutions. On the other hand, fuel cells, which most generally speaking convert chemical energy of a fuel (hydrogen, alcohols, sodium borohydride, and so on $)^{3-6}$ to electrical energy, provide an alternative to batteries for both mobile and stationary applications. Unfortunately, most of the fuel cell catalysts are based on platinum, which is also a critical element with very high market price. However, one should look at the same problem from the perspective of the underlying 
mechanisms of energy conversion in batteries and fuel cells. Battery operation involves phase transition of bulk electrode material which, in an ideal scenario, is completely converted to another phase during battery charge/discharge. ${ }^{7}$ This guaranties a well-defined change in Gibbs free energy $(\Delta G)$ for the reaction taking place, setting the operational voltage, while ensuring a flat discharge plateau. In contrast, electrocatalytic reactions in fuel cells take place at the catalyst/solvent interface. This comparatively small region dictates the performance of the entire system in the most fundamental way. Basic thermodynamics states that for a given reaction taking place in a fuel cell system, $\Delta G$ is determined by temperature, concentration, and pressure of reactants. Hence, if a fuel cell operates under stationary conditions, the voltage output should be rather constant. The fact that the interface is responsible for the operation of (electro)catalyst has important implications for understanding and tuning its properties. ${ }^{8-10}$ However, it also gives a great opportunity to develop this area into an amazing playground with numerous approaches to overcome the scarcity of the best elemental electrocatalytic materials. It is rather natural that a vast number of surface science methods is applied to describe the properties of different systems intended to serve as electrocatalysts. Nevertheless, the complexity of heterogeneous systems in general hinders the application of these methods to their full potential. ${ }^{11}$ The use of model systems such as single crystals, films, or particles on different supports simplifies the problem to a certain extent and allows gathering crucial information regarding the interface state. Theoretical methods in (electro)catalysis, mostly based on density functional theory (DFT) coupled to the computational hydrogen electrode, CHE, have proven their pivotal role in the understanding and development of novel catalytic materials. The ability to calculate adsorption properties, reaction pathways, and activation energies for surface chemical reactions with the accuracy close to the experimental ${ }^{12,13}$ one is of great importance for shifting the electrocatalyts search approach from trial-and-error to rational design. This is further supplemented by finding general relationships and universality in heterogeneous catalysis $^{14-16}$ and by the power of modern computational facilities which allow relatively quick screening of a large number of potentially new (electro)catalytic systems. ${ }^{17}$

Going back to the problems of scarcity and the price of noble metals used in electrocatalysts, the fact that the interface is responsible for the materials performance implies that the underlying bulk material is much less important, unless it significantly affects the chemical properties of the surface layer. Hence, a number of thin film (TFC) and core-shell catalysts (CSC) have been developed. This was motivated by the idea of substituting the expensive bulk of a noble catalyst with cheaper materials, assuming that such replacement does not affect the surface properties. Both TFC and CSC are formed in such a way that coating or shell is grown over a support or core. Coating/shell has the catalytic function and consists of either a single catalytically active metal or a multimetal phase. Formation of multimetallic catalyst layer can boost the catalytic performance, compared to the monometallic ones. ${ }^{18,19}$ There are many strategies devoted to the synthesis of thin catalyst layers over foreign substrates. ${ }^{20-22}$ However, the question is whether it is possible to predict the properties of TFC and CSC and tune them so that the maximal catalytic performance for a given reaction is achieved, remain. The compositions of support (core) and overlayer (shell) are pivotal in determining the properties of the catalyst and the ways in which they interact are worth exploring. In TFC (or CSC), the underlying support can affect the surface composition and the electronic structure of the coating (shell). There are two possible sources of the influence of the support: (1) due to the chemical environment (ligand effect) or (2) due to the lattice mismatch (geometric strain effect). Elastic deformation has long been recognized as a tool for modifying surface reactivity. ${ }^{2,24}$ It should be noted that outside the elastic regime, different types of relaxation may happen. ${ }^{25}$ Understanding how different properties of thin catalyst film change with its thickness and the ability to predict such properties are of great importance for practical applications and is the focus of the present perspective.

\section{ELECTROCATALYSIS vs HETEROGENEOUS CATALYSIS}

In the previous section, an important property of electrochemical systems was outlined, their complexity. Hence, it is important to understand the difference between electrocatalyst and heterogeneous catalyst. While electrocatalysts can be considered as a class of heterogeneous catalysts, the existence of electronic/ionic conductor interface (i.e., electrode) makes the situation much more complicated. Due to the presence of the electrified interface, species in the electrolyte strongly adsorb on the electronic conductor surface. These include (solvated) ions, solvent molecules, electroactive species, and reaction intermediates. As a result of charge separation at the electrode, an electrical double layer (EDL) is formed, irrespective of the presence of the electroactive species. The thickness of EDL depends on the concentration of the ionic species from the electrolyte side (through the ionic strength of the solution), and for concentrated electrolytic solution (always used in electrochemical measurements), it is of the order of $10^{-9} \mathrm{~m}$. Considering that the electric potential drop goes from electronic conductor surface through the EDL and assuming it is only $1 \mathrm{~V}$, we come up with the electric field of the order of $10^{9} \mathrm{~V} \mathrm{~m}^{-1}$. This is an extremely strong electric field which is rather difficult to achieve in a laboratory. Another characteristic of (almost all) electrocatalytic processes is that they proceed in highly corrosive environments, either highly acidic or highly alkaline. This can have a strong influence on the stability of electrocatalytic materials, additionally limiting the range of potential electrocatalysts. Besides these "static" parameters, one must not forget that the electrode potential is the main driving force for the desired electrocatalytic reaction, but it also drives parallel surface processes. These can affect the rate of the desired reaction in many ways. Taking platinum as an example, there are distinct surface processes including hydrogen adsorption/desorption (at potentials close to $0 \mathrm{~V}$ vs reversible hydrogen electrode, RHE) and platinum surface oxidation at potential above $0.6-0.8 \mathrm{~V}$ vs RHE. The later process is known to hinder both hydrogen oxidation reaction (HOR) at very high overpotentials and also oxygen reduction reaction (ORR), ${ }^{26}$ as will be explained later on. Hence, one can say that an electrocatalyst surface is restless and that electrocatalytic process cannot and must not be considered separately from the inherent surface process taking place on the electrocatalyst surface. Finally, realistic electrocatalysts are heterogeneous, usually in the form of nanoparticles deposited over a properly chosen support which in some cases can contribute catalytic activity and catalyst stability. Here mass transfer limitations can play an equally important role as 
intrinsic catalytic activity. Bearing all in mind, in contrast to other heterogeneous catalysts, there are many additional factors in need of considering when developing new electrocatalytic materials. This also presents a great challenge for modeling approaches which will be addressed in the next section.

\section{METHODOLOGICAL APPROACHES IN DEVELOPING NEW ELECTROCATALYST}

Considering the complexity of electrified interfaces, there is a great challenge to take all the relevant parameters into the consideration. However, modeling can be seen as a tool for navigating a complex multiparametric space and identifying the main factors responsible for catalytic activity. The question remains: how to choose the correct activity descriptors. ${ }^{12,13}$ For example, in the hydrogen evolution reaction (HER) there is a link between HER exchange current density and metalhydride formation energies. ${ }^{27}$ Hence, a plausible strategy in the search for new electrocatalytic materials is screening through numbers of possible candidates using a quantity which is determined outside an electrochemical system. In this case, there is no need to worry about all the "complications" when switching from heterogeneous catalyst to electrocatalyst, mentioned in the previous section. The main tool in this quest is, unambiguously, DFT in one of its many implementations, local density approximation $\left(\mathrm{LDA}^{28}\right)$, generalized gradient approximation (GGA, ${ }^{29}$ the most widely used approach), many other like meta-GGA and hybrid-GGA, and so on. ${ }^{30}$

However, if electrocatalytic material is to be properly modeled from first-principles, one has to consider (i) electrode potential, (ii) presence of the electrolyte, (iii) $\mathrm{pH}$ effects, and (iv) inherent surface processes of an electrocatalyst (i.e., those independent of the presence of the electroactive species). In order to include the mentioned effects, one has to step back from modeling well-defined surfaces of bare metal slabs and go into building more complex models. This brings us to the firstprinciples electrochemistry $\left(\mathrm{FPEC}^{31,32}\right.$ ), an exciting and quickly developing field. Within FPEC, the main task is to link metal phase potential $\left(\phi^{\mathrm{M}}\right)$ as the main driving factor for electrocatalytic reaction, charging the EDL, driving "inherent" surface process on the electrocatalyst, and solvent effects (either explicitly or implicitly) with electrocatalyst performance. For this task, DFT methods still remain at the core, providing atomic-level understanding of the electrocatalytic process. Within FPEC, DFT is the main quantum chemical method to capture self-consistent coupling between $\phi^{\mathrm{M}}$ and the properties depending on it, ${ }^{33}$ but it is often complemented by classical molecular dynamics (MD) or Monte Carlo (MC) simulations and double layer theories of different complexity. ${ }^{33-35}$ There are many approaches of FPEC, as summarized in Figure 1, and their full overview is a task for itself, particularly considering the perspective nature of this contribution. However, we recommend two review papers of Eikerling and co-workers which address this subject in detail. $^{33,36}$ Nevertheless, we shall mention the most widely used approach called computational hydrogen electrode (CHE), ${ }^{37-39}$ which strictly speaking is not the FPEC scheme. $^{36}$ Within CHE, the potential scale is linked to a thermodynamic reference (equilibrium hydrogen electrode), and there is a coupling of electron and proton transfer ${ }^{40}$ so that there is a term $-e U$ added to the reaction enthalpy, which is calculated self-consistently. In this approach $U$ is the potential

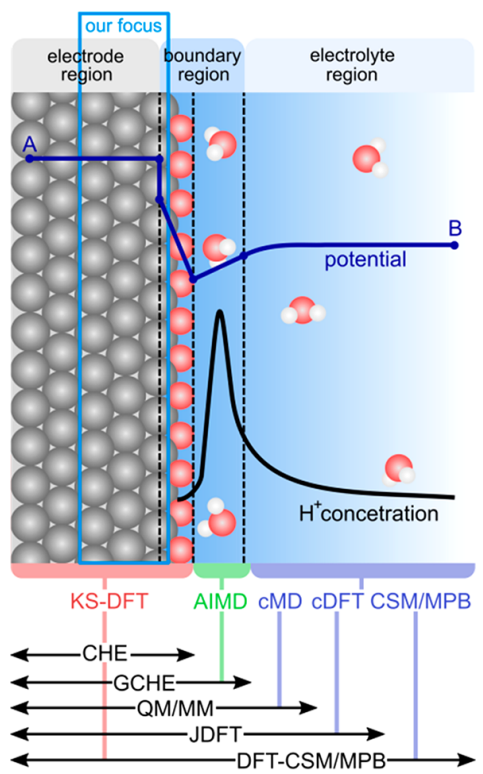

Figure 1. Schematic of the electrode-electrolyte interface, showing the electrode region, electrolyte region, and boundary region inbetween. Simulation methodologies for different regions are indicated at the lower edge. Different flavors of first-principles approaches to study the electrochemical interface are indicated along the bottom rail. For details see ref 36 . In the figure, we identified the main focus of this perspective. Adapted from ref 36 with permission Copyright 2018 from Elsevier.

relative to the reference electrode. This approach has proven its suitability in analyzing mechanisms and pathways of electrocatalytic reactions in fuel cells, batteries, electrolyzers, fuel production, and $\mathrm{CO}_{2}$ reduction. ${ }^{36}$ Colloquially speaking, it treats every electrocatalyst as a heterogeneous catalyst and introduces potential scale using the counter electrode in equilibrium. Hence, accuracy of CHE is linked to the accuracy of the computational scheme used to evaluate reaction enthalpies, which is, as a rule, DFT. We can see the main strength of this method in comparative analysis of different materials, for which we can make a strong parallel with electrochemical practice. In electrocatalysis, different materials are most frequently evaluated in such a way that measured currents are compared at a given electrode potential. In this case, the term added to the reaction enthalpies which contains electrode potential, for different electrocatalytic materials simply shift the enthalpy by a constant factor and does not change the order of catalytic activities. Hence, in order to capture the trends with modeling in most cases, it is sufficient to treat an electrocatalyst as a heterogeneous catalyst and possibly consider the solvent effect implicitly, taking into account stabilization of adsorbed reactive species and intermediates due to the solvation/hydration. ${ }^{41}$ In fact, there are cases where the way of including solvation does little to influence the activity descriptors ${ }^{42,43}$ and the inclusion of a few explicit solvent molecules is enough to capture the correct behavior of the system. ${ }^{44}$ One of the most challenging situations to tackle in simulating an electrochemical system with a typical DFT approach is when reaction intermediates at zero overpotential are not stable on the catalyst surface. However, catalysts exhibiting this trait tend to be outperformed by the ones which do not. ${ }^{45}$ Finally, we have to notice that, in spite the rapidly growing field of FPEC, in the 

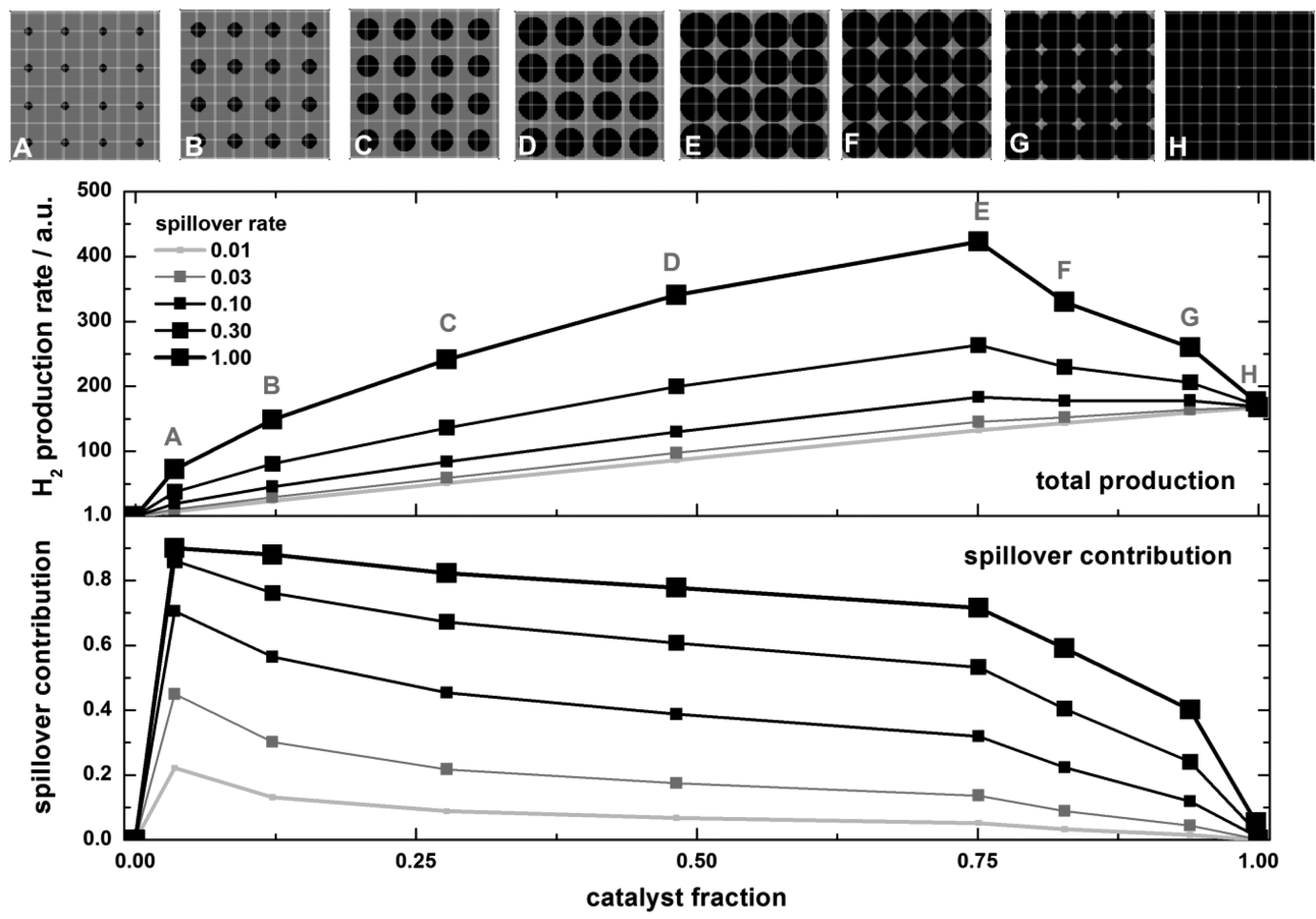

Figure 2. (Upper panel) geometry setups for the systems used in presented KMC simulations. As going from parts A to $\mathrm{H}$, the coverage of the support by the catalyst is increasing. The case when there is no $\mathrm{C}$ on the support results with no $\mathrm{H}_{2}$ production, while the case when the surface coverage by $\mathrm{C}$ is 1 represents the case of a massive catalyst. (Lower panels) total $\mathrm{H}_{2}$ production rate and the spillover contribution to the total $\mathrm{H}_{2}$ production for different spillover rates. Reproduced from ref 47. Reproduced by permission of the PCCP Owner Societies. Copyright 2017.

existing literature electrocatalysts are dominantly treated as heterogeneous catalysts (i.e., electrochemical reactions are considered at the solid/vacuum interface).

While we have outlined the main focus of the present work, we must mention that DFT, while most frequently used in modeling of electrocatalytic materials, has limitations which do not allow it to go to certain temporal and spatial domains. Besides its intrinsic complexity, electrified interfaces, in principle, span over distances which cannot be treated routinely using DFT. This relates both to the direction perpendicular to the electrified interface (electrolyte side) and in lateral dimension, if a more realistic situation of supported catalyst is to be considered. In this case, Monte Carlo methods can be applied either to sample the solvent side of the electrified interface ${ }^{36}$ or can be used to investigate catalyst performance using a preassumed microkinetic model. The later approach can provide atomic-level information on the catalytic process at time and space domains similar to those in the experiment. ${ }^{46}$ There are many approaches to Monte Carlo simulations, and as an example, we mention kinetic Monte Carlo (KMC) modeling of supported hydrogen evolution catalysts where the focus was on the contribution of the catalyst support on the hydrogen production via spillover contribution. ${ }^{46,47}$ While in this particular case the emphasis was on the analysis of the effects of different rates of elementary processes on the catalyst performance and the catalyst/support interplay (Figure 2), we note that reproduction of experimental data requires intimate knowledge of the rates of the elementary process. The rates can be obtained from experiment, ${ }^{48}$ or, again, calculated $a b$ initio. In the latter case, this usually means transition state theory in combination with DFT calculations for barrier height and prefactor estimates. $^{49,50}$

Besides DFT, in many of its formulations, Monte Carlo modeling, and their combinations, there are other computational approaches which are used to understand the behavior of electrocatalysts, but we do not aim to provide their overview here. Instead, considering complexity of the electrified interface and the current state in the literature, we focus here on the properties of electrocatalytic materials as seen from the metal side using electronic structure methods (Figure 2, blue box). In particular, we provide perspective on the understanding of the properties of the thin film electrocatalysts and core-shell electrocatalysts considering the differences between the support (core) and the overlayer (shell) as the function of number of layers in the overlayer (shell). We note that the field of TFC/CSC is vast, and electrocatalysis is only a small part of possible application of TFCs and CSCs. Also, in studying TFCs and CSCs, there is a number of important aspects, starting from synthesis, physical and chemical characterization, and finally testing their performances for real life applications. We do not aim to provide a detailed overview of all these aspects and refer possible readers to specialized reviews on these topics. ${ }^{22,51}$ In order to make this perspective acceptable to both experimentalists and theoreticians, we aim to provide a joint picture drawn by some of the most important experimental and theoretical findings related to the interplay between the support (core) and overlayer (shell) in electrocatalytic systems. 


\section{CAPTURING TRENDS WITH THEORY}

In reality, catalysts typically come in the form of nanoparticles. Even rather small nanoparticles (for example, a $4 \mathrm{~nm} \mathrm{Pt}$ nanocatalyst for oxygen reduction reaction) consisted of several thousands of atoms. In situations when classical or parametrized force fields are not sufficient to properly describe the system, as in the case of metals, this number of atoms is rather challenging even for the most powerful supercomputers. Studies where entire nanoparticles are treated explicitly are very rare. ${ }^{52-54}$ Instead, it is common to investigate parts of the catalyst (nanoparticle) surface to observe the effects of coordination, local chemical environment, and other factors. Given that the sample of the surface is large enough, some basic properties of electrocatalyst can be captured. Here we shall address the electronic structure, surface segregation processes, and dissolution of the surface layer, which are crucial for the electrocatalyst performance.

Electronic Structure and Adsorption Trends. Theoretical electronic structure methods such as DFT provide detailed information regarding the electronic structure of solid surfaces. However, the problem of finding a link between the details of the electronic structure and the reactivity of solids remains. Hammer and Nørskov formulated a concept, known as the $d$ band model, which describes adsorption trends on transition metal surfaces using the position of the metal's $d$-band. ${ }^{55,56}$ This model provides a simple connection between the electronic structure and the reactivity of transition metal surfaces as well as their alloys and overlayers. The key parameter determining the adsorption strength, namely, the energy of the $d$-band center $\left(E_{d \text {-band }}\right)$, can be obtained both experimentally (from spectroscopic methods) and by theoretical calculations. ${ }^{57}$ According to the $d$-band model, the interaction of an adsorbate with metal can be thought of as a two-step process. First, the electronic state of the adsorbate widens due to its interaction with the metal's wide, half-filled $s$ states (which holds true for all transition metals). Next, the sowidened adsorbate state interacts with metal's narrow $d$-state, giving rise to bonding and antibonding states. Their relative occupancies, determined by the positions of the adsorbate state and the metal's $d$-states, dictate the strength of the overall interaction. ${ }^{58}$ In general, the $d$-band model shows that the adsorption of many simple adsorbates is stronger when the $d$ band center is closer to the Fermi level. As the $d$-band center and adsorption energies of reactants and reaction intermediates are connected mutually and can be identified as activity descriptors, ${ }^{12,13}$ the understanding of the electronic structure enables prediction of surface reactivity and electrocatalytic activity. Typically, $d$-band center is calculated as the first moment of the $d$-band. The $d$-band model is largely discussed in the current literature, and further improvements are suggested. ${ }^{59,60}$ Through the identification of (electro)catalytic descriptors ${ }^{12,13,37}$ and increased understanding of different ways to tune the electronic structure of the surface, it became possible to rapidly analyze vast number of novel systems (realistic and hypothetical) leading to the development of various screening schemes for identification of new electrocatalysts. ${ }^{61}$ Most of the existing studies rely on the modeling of extended surfaces at the solid/vacuum interface, under the assumption that the presence of solvent and the electric field at the interface in an electrochemical system do not affect conclusions regarding the activity (trends). These assumptions are contained in the framework of already mentioned $\mathrm{CHE}$ where solvent is not treated explicitly, while it also does not consider the effects of the electrode potential on bond strengths, adsorbate formation, and solvent polarization. ${ }^{36}$ As formulated and presented for the case of oxygen reduction reaction, ${ }^{37} \mathrm{CHE}$ is in line with (single) descriptor approach which is the consequence of scaling of adsorption energies of reaction intermediates. However, the main trends are being properly described using such approach, even without detailed kinetic modeling (Figure 3).

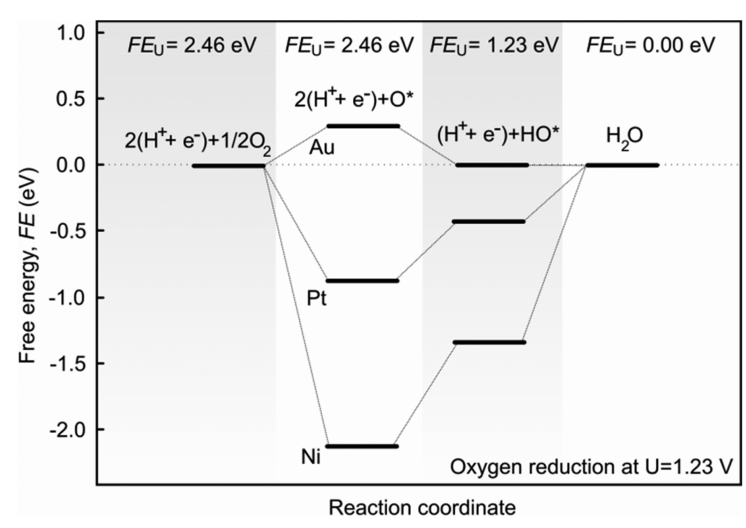

Figure 3. Free-energy diagram for oxygen reduction at the equilibrium potential $U_{0}=1.23 \mathrm{~V}$ over $\mathrm{Pt}, \mathrm{Au}$, and $\mathrm{Ni}$. Adapted with permission from ref 37. Copyright 2004 American Chemical Society.

Although neglecting the solvent and electrode potential seems to be an extreme simplification, the results obtained through these screening studies show that the main physics and chemistry of electrocatalytic interface are actually captured by theory at the solid/vacuum interface. As an example, we mention the study of Xin et al. ${ }^{61}$ who developed a scheme that connects the geometric structure and local chemical environment of active $\mathrm{Pt}$ sites to the local chemical reactivity toward electrochemical oxygen reduction reaction (Figure 4).

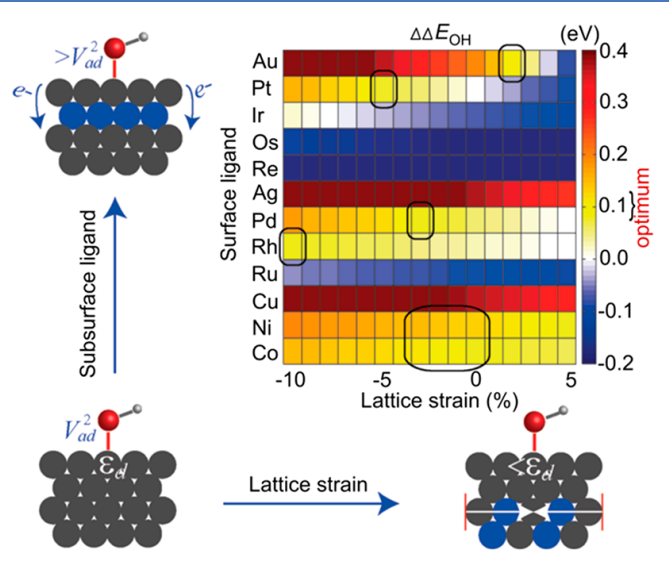

Figure 4. Model prediction of $\mathrm{OH}$ binding energies on Pt monolayer alloy surfaces with varying subsurface ligand $(1 \mathrm{ML})$ and lattice strain $(-10 \%$ to $5 \%$ expansion). Marked regions depict the alloy systems with desired catalytic properties $(+0.1 \mathrm{eV}$ weaker $\mathrm{OH}$ binding than pure $\mathrm{Pt}$ ). Inserts show different mechanisms by which the $\mathrm{OH}$ adsorption energy changes. Reprinted with permission from ref 61 . Copyright 2012 American Chemical Society. 


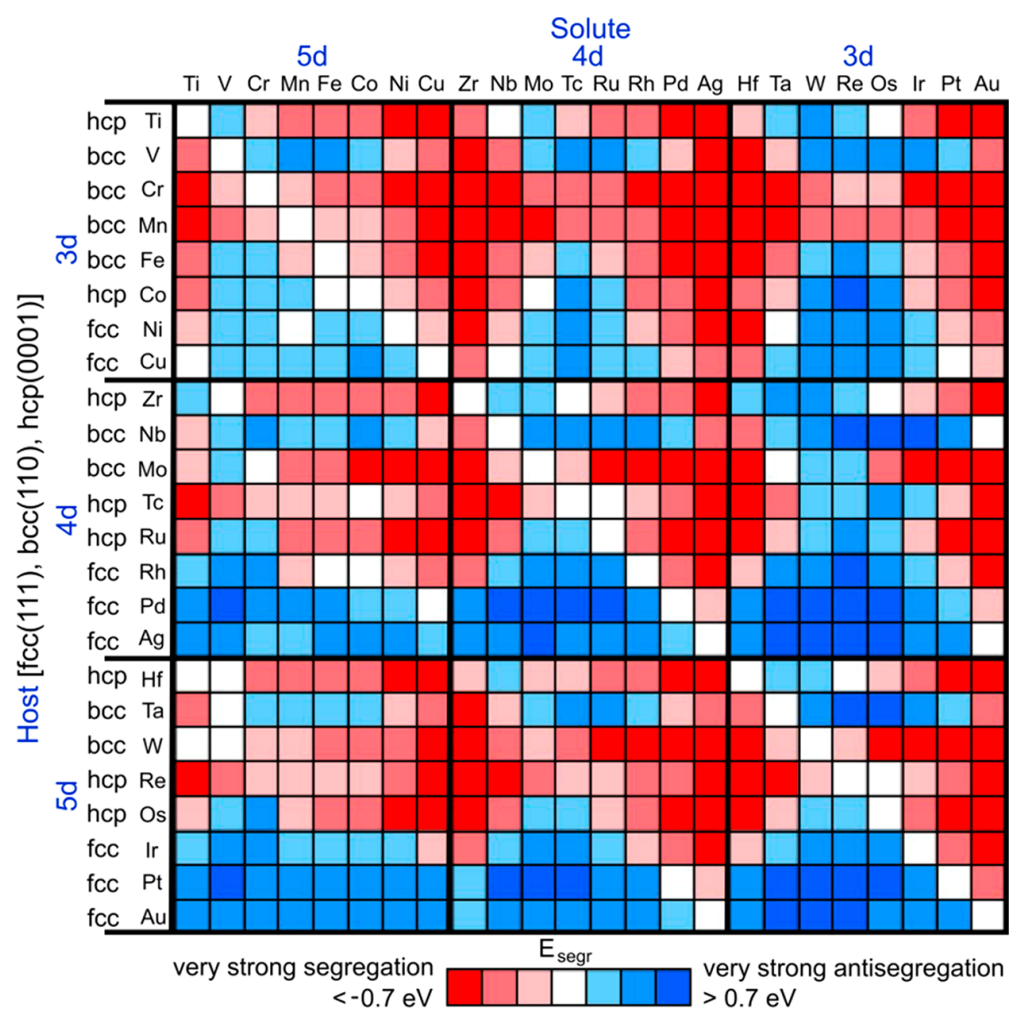

Figure 5. Surface segregation energies of transition-metal impurities (solute) for the closed-packed surfaces of transition metal hosts. Adapted from ref 66. Copyright 1999 by the American Physical Society.

The introduction of diluted heteroatoms to the metal surface (sometimes called single atom catalyst ${ }^{62}$ ) affects the atoms of both metals. Here the heteroatom is present in a much lower amount and substantially more affected. This is reflected in the shape of its $d$-band and can in some cases lead to the heteroatom appearing as it was isolated due to the weak interactions. ${ }^{63,64}$ Discussing the oxidation states of (apparently) isolated atoms, particularly in solids, is challenging. ${ }^{65}$ Weak interactions are, however, likely to lead to compromised stability followed by segregation or dissolution.

Surface Segregation Processes. As the surface electronic structure of a surface dictates its reactivity and activity, different factors affecting the electronic structure must be considered. In multicomponent systems, surface composition can differ from the bulk composition due to surface segregation processes. In other words, surface layer(s) can be enriched by one of the components of the system. A seminal work by Ruban et al. ${ }^{66,67}$ demonstrated the power of theoretical tools for the estimation of segregation trends in alloys, providing a simple rule of thumb (with certain exceptions) saying that the alloy component which has the lowest surface energy will segregate toward the surface of the alloy (Figure 5). When the available databases of surface energies of metals ${ }^{68,69}$ are combined, segregation trends in multicomponent systems can be derived.

In the mentioned work, the surface segregation energies $\left(E_{\text {seg }}\right)$ were calculated as the difference between the effective chemical potential of the impurity in bulk and in the given surface layer of a given bimetallic system. Some simplified schemes to calculate $E_{\text {seg }}$ have been offered over time. For example, the work by Ma and Balbuena has suggested that $E_{\text {seg }}$ can be calculated as the total energy difference between the segregated and nonsegregated surface, either at the solid/ vacuum interface or under some adsorption conditions. ${ }^{70,71}$ The latter is of particular importance for electrochemical systems, and we note that the results presented in Figure 5 are related to the solid/vacuum interface. Under electrochemical conditions, adsorption at the solid/electrolyte interface can affect the equilibrium between the surface and subsurface layers and affect the segregation trends. We note that this question is not addressed in detail, but the methodology generally exists and the understanding of the segregation process at the solid/vacuum interface presents the first step to be made. Namely, it was shown that the segregation under adsorption conditions is linked to segregation under vacuum conditions and the surface-adsorbate binding strength. ${ }^{71}$ As electrode potential affects the adsorption processes on the electrode, the necessary step would be to also link electrode potential to surface segregation processes under electrochemical conditions.

Dissolution of Electrocatalysts. The catalyst stability under operating conditions was always considered as extremely important, but it appears that just recently scientific community paid more attention to solving this problem. ${ }^{72,73}$ While there are many catalyst degradation mechanisms, dissolution is the most intensively investigated one, largely stimulated by the development of in situ techniques for monitoring catalyst dissolution. ${ }^{74,75}$ Considering the complexity of an electrochemical interface and the number of factors which can affect the dissolution process (such as the electrolyte, presence of ligands and so on), the calculation of accurate dissolution potentials/energies can be somewhat difficult. However, the situation can be simplified, if one assumes that the energy required to remove an atom from the 
surface layer of the catalyst is directly related to the dissolution potential/energy. ${ }^{76}$ For example, if one composes a galvanic cell with a given electrocatalyst as one electrode and the bulk electrode of the element whose dissolution is considered (Figure 6), the electromotive force is determined by the

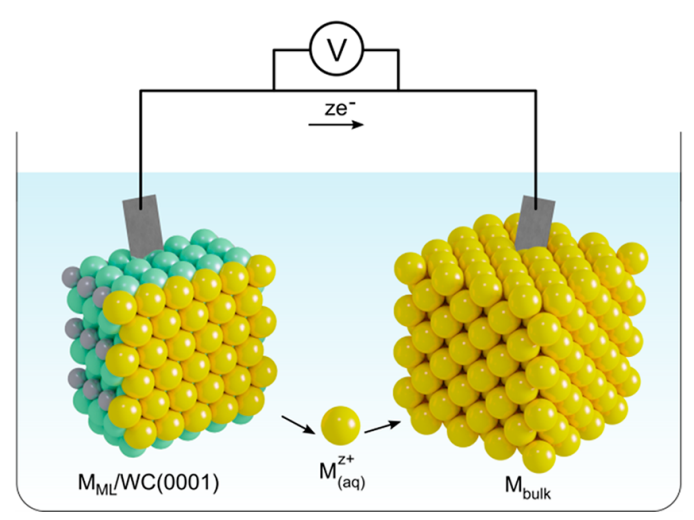

Figure 6. Galvanic cell considered for the evaluation of the dissolution potential of monolayer catalyst over the WC substrate. Adapted from ref 77. Copyright 2013 Hydrogen Energy Publications, LLC. Published by Elsevier Ltd. All rights reserved.

difference between the binding energy of a given elements in the catalyst layer and the cohesive energy of the pure element. ${ }^{74}$ Knowing the experimental value of the dissolution potential of the pure phase, one can estimate the dissolution potential for the thin film catalyst. Going further from thermodynamics, it is important to note that DFT modeling was used to provide mechanistic insights into dissolution of electrocatalysts, and a significant amount of work has been done for the case of $\mathrm{Pt}^{78,79}$ More details about modeling kinetics of Pt dissolution, for which statistical framework is used, can be found in recent review of Eslamibidgoli et al. ${ }^{33}$

In the forthcoming text we shall briefly overview some results regarding the application of thin catalyst films over extended polycrystalline and single crystal surfaces and coreshell nanoparticles focusing on the fuel cell electrocatalysis.

\section{THIN ELECTROCATALYST FILMS ON DIFFERENT SUBSTRATES}

Metallic Layers on Metallic Substrates. Metals most interesting for electrocatalysis are located close to $\mathrm{Pt}$ in the periodic table of elements. These include $\mathrm{Pt}, \mathrm{Pd}, \mathrm{Ru}, \mathrm{Rh}, \mathrm{Ir}, \mathrm{Ni}$, and coinage metals. Except for $\mathrm{Ru}$, which grows in a hexagonal lattice, these metals possess the face-centered cubic lattice. Hence, the deposition of these metals on each other should mainly results in an epitaxial growth. Due to lattice mismatch between the substrate and the overlayer, however, some surface strain appears, either compressive or tensile. It is well accepted that tensile strain shifts $E_{d \text {-band }}$ toward higher energies while compressive strain causes down-shift of the $d$-band center. This is intimately connected with reactivity and activity changes, as can be expected on the basis of the $d$-band center model.

The formation of atomically thin overlayers on well-defined metallic surfaces can be achieved electrochemically, and some of the first reports regarding electrocatalyst production come from the group of Radoslav Adžić, who used galvanic displacement technique to deposit monolayers of platinum group metals on metallic substrates, either single crystals or nanoparticles. ${ }^{80-82}$ These studies were mainly directed toward the development of novel oxygen reduction reaction (ORR) catalysts. The authors did observe that in some cases the monolayers are not perfect but rather disordered. ${ }^{82}$ However, they pointed out that was not actually a drawback in terms of the electrocatalytic activity. Even in the first reported studies it became clear that the surface reactivity of $\mathrm{Pt}$ monolayers is greatly affected by the underlying substrate, while the increased ORR activity was followed by hindered $\mathrm{OH}$ adsorption observed in cyclic voltammetry measurements. Considering the series of Pt monolayers on different substrates, ${ }^{83}$ combined experimental and theoretical work showed that the electronic structure of a Pt monolayer is affected by the underlying substrate and that there is a volcano-type relationship between the $E_{d \text {-band }}$ of Pt atoms located in the catalyst surface layer and the catalytic activity. It is important to notice that in theoretical studies, catalytic overlayers are almost always perfect, epitaxial layers over foreign substrate. This diverges from reality to a certain point as there are always some defects in realistic systems. ${ }^{25}$

There is another series of papers focusing on Pt alloys with the $3 \mathrm{~d}$ series of transition metals, showing enhanced ORR activity for certain $\mathrm{Pt}_{3} \mathrm{M}$ systems $(\mathrm{M}=\mathrm{Ni}$, Co and other $3 \mathrm{~d}$ elements). The study was initiated on supported nanoparticles, ${ }^{84-86}$ but it clearly indicated that the formation of a Pt-enriched surface (formation of "Pt-skin") over the Pt-M core is beneficial for increased ORR activity. When this research was shifted toward extended polycrystalline surfaces $^{87,88}$ and well-defined single crystal surfaces ${ }^{89}$ and combined with theoretical DFT calculations, the links between the $d$ band center or oxygen adsorption energy, on one side, and the catalytic activity, on the other, appeared (Figure 7).

Due to dissolution of the alloying element from the surface layers of the $\mathrm{Pt}_{3} \mathrm{M}$ surface layer is formed of pure Pt. This layer is being compressed over the substrate, resulting with small but crucial down-shift of the $d$-band center, which in turn results with hindered formation of $\mathrm{OH}_{\text {ads }}$ on the surface. As a consequence, the surface of the catalyst is less covered by spectating species, resulting in increased ORR activity. It is important to note that on the single crystal surface change of the composition is observed only in the first two layers. ${ }^{89}$ The first surface layer was found to be consistent only of $\mathrm{Pt}$, while the second surface layer was enriched in $\mathrm{Ni}$ in comparison to bulk. This suggests that small changes of the composition affects only the topmost layers of the catalyst boost performance to a great extent. Moreover, this study of Stamenkovic et al. is an excellent example of how segregation-driven composition changes in surface layers affect the electronic structure and the activity of electrocatalysts. An idea of formation of a Pt-skin over lattice-contracted Pt-based alloys was widely accepted and utilized to produce numerous electrocatalysts with controlled surface composition, such as $\mathrm{Pt}-\mathrm{Cu}$ with controlled surface composition, ${ }^{90-92} \mathrm{Pt}-\mathrm{Y}$ and $\mathrm{Pt}-\mathrm{Sc}$ ORR electrocatalysts, ${ }^{13}$ and others. However, we also must observe that in this activity rate, stability issues were paid very little attention and they started to be addressed in a systematic manner in the past decade. ${ }^{93}$

Similar strategies were also employed in the development of hydrogen evolution (HER) catalysts. However, in an acidic electrolyte, hydrogen electrode reactions are much faster than oxygen electrode reactions, ${ }^{94}$ their activity improvements do not present a great challenge from a practical point of view, 

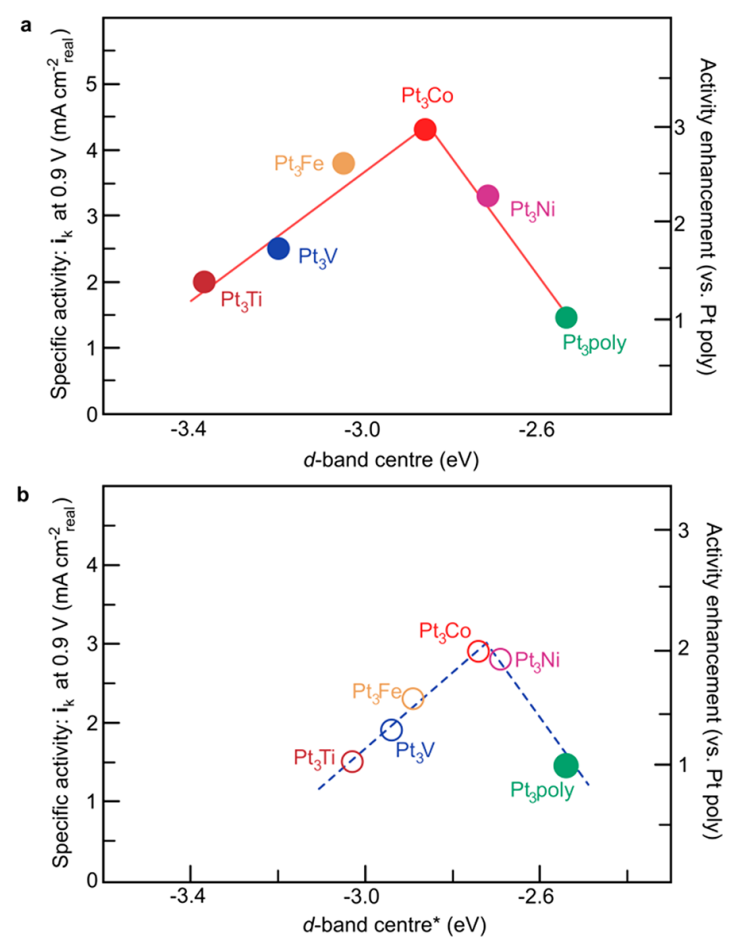

Figure 7. Relationships between the catalytic properties and electronic structure of $\mathrm{Pt}_{3} \mathrm{M}$ alloys. (a,b,) Relationships between experimentally measured specific activity for the ORR on $\mathrm{Pt}_{3} \mathrm{M}$ surfaces in $0.1 \mathrm{M} \mathrm{HClO}_{4}$ at $333 \mathrm{~K}$ versus the $d$-band center position for the Pt-skin (a) and Pt-skeleton (b) surfaces. Part b shows the $d$ band center values established in UHV, which may deviate in the electrochemical environment due to dissolution of non-Pt atoms. Reprinted from ref 88. Copyright 2007, Springer Nature.

and it also not motivated to a great extent, when compared to the case of ORR. It is interesting to mention that the changes of the strain in catalyst films have unambiguously been confirmed and separated from ligand effect when concerned with HER activity. ${ }^{95}$ Experiments performed upon the application of elastic strain to thin catalyst films have shown that strain tunes reactivity in a controllable fashion consistent with the qualitative predictions of the HER volcano plot and the $d$-band theory (Figure 8 ). For example, the activities of $\mathrm{Ni}$ and $\mathrm{Pt}$, which are located on the strong bonding HER volcano branch, were accelerated by compression, while the activity of $\mathrm{Cu}$, located on the weak bonding volcano branch, was accelerated by tension.

It is important to note that in the case of hydrogen electrode reactions, the hydrogen binding energy was frequently taken as an activity descriptor, in the spirit of HER activity volcano established by Trassati, ${ }^{27}$ and in some cases it turned out to be a better measure of activity than the $d$-band center. ${ }^{96}$

Metallic Layers on Nonmetallic Substrates. While there are many examples of the atomically thin electrocatalyst films on metallic substrates, there are significantly fewer examples of thin film electrocatalysts over nonmetallic substrates. It is, however, possible to find adequate substrates on which epitaxial growth of overlayer is possible, like in the case of the (111) surface of $\mathrm{SrTiO}_{3}{ }^{97}$ where strain is found to be an effective tool to tune ORR catalytic activity. Another example is tungsten carbide (WC) which has a hexagonal lattice, and it is possible to grow layers of electrocatalytically

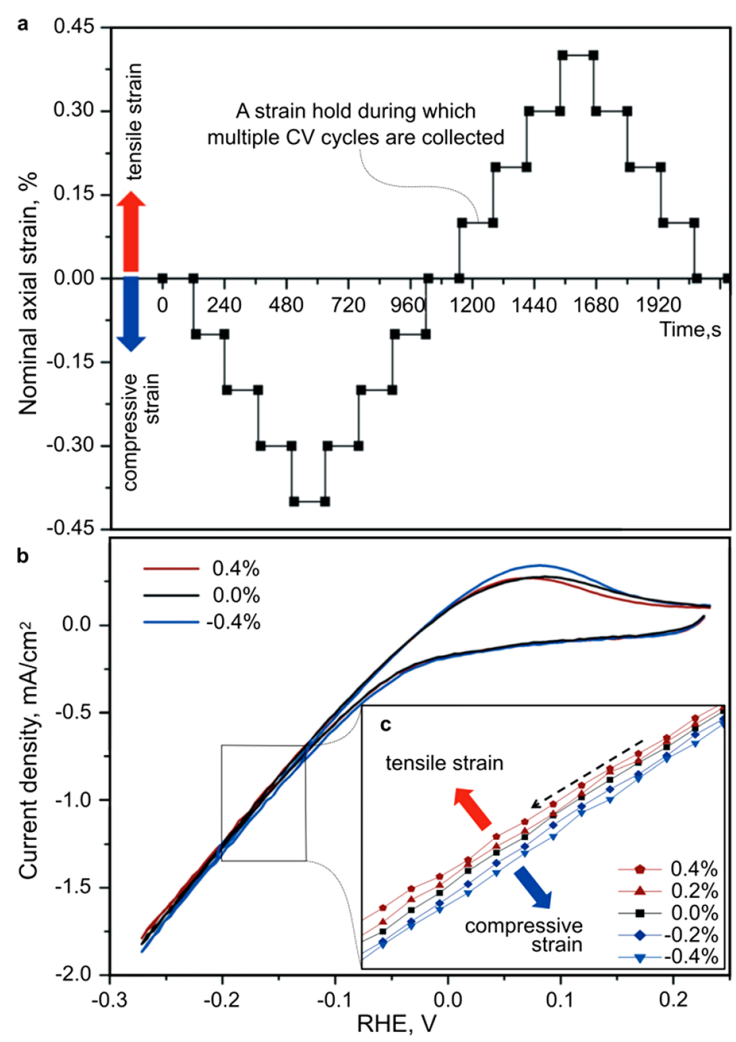

Figure 8. (a) Illustration of the loading history on the PMMA (poly(methyl methacrylate)) substrates, showing progressively increasing compressive and tensile strains. The Pt films deposited on PMMA inherit the substrate strains. (b) Representative CVs obtained at strains of $-0.4 \%, 0 \%$, and $0.4 \%$, where negative values are compressive and positive values are tensile. (c) Magnified view of part $\mathrm{b}$ in the HER region showing only the reduction sweep at five different strain values. Note the systematic shift in the CV curves with strain. Adapted from ref 95. Copyright 2016, John Wiley and Sons.

relevant metals over densely packed WC(0001). In fact, the interest to WC in the field of (electro)catalysis dates back to the first reports of Pt-like behavior of WC. ${ }^{98}$ As the electronic structure of WC is similar to that of platinum, a small ligand effect was assumed suggesting this material as perfect support for thin Pt layers in new generation of electrocatalysts. As WC easily oxidizes, most of the reports was focused on HER ${ }^{99-101}$ and reported either similar or improved HER activity or Pt (mono)layer catalysts deposited onto WC. However, the rigorous activity measurement ruled out the influence of WC on the intrinsic HER activity of Pt@WC catalyst in comparison to pure $\mathrm{Pt}^{102}$ Due to the hexagonal lattice of WC, theoretical analysis of many transition metal overlayers on it is rather a routine task. Therefore, some hypotheses regarding the effects of substrate can be easily tested. First, the electronic structure of densely packed WC(0001) (both $\mathrm{W}$ - and C-terminated) is far from that of densely packed $\operatorname{Pt}(111) .{ }^{103}$ Next, due to the difference in the lattice constants, $\mathrm{Pt}$ (as well as Pd and other "interesting" metals) are subjected to tensile strain, when epitaxially grown on $\mathrm{WC}(0001) .^{103}$ Based on the existence of tensile strain one would expect pronounced destabilization of the $\mathrm{Pt} d$-band and increased reactivity, followed by a decrease in HER activity. This is, however, not the case due to the extreme ligand effect of WC substrate. Nevertheless, this effect is quickly smoothed out, 
already for the second Pt or Pd layer, leaving only the strain influencing the electronic structure of the very surface (Figure 9). The dramatic electronic effect of WC was observed for

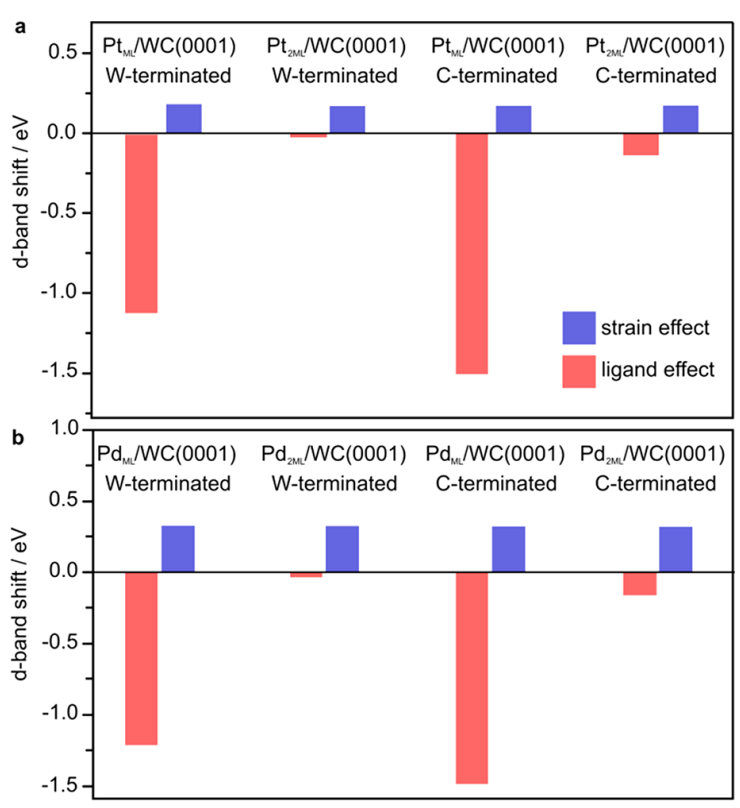

Figure 9. Individual contributions of the ligand and the strain effect on the $E_{d \text {-band }}$ shifts of WC-supported Pt (a) and Pd (b) overlayers. Adapted from ref 103. Copyright 2013 Hydrogen Energy Publications, LLC. Published by Elsevier Ltd. All rights reserved.

other monolayers of transition metals (including $\mathrm{Cu}, \mathrm{Ru}, \mathrm{Rh}$, $\mathrm{Ag}, \mathrm{Ir}, \mathrm{Au}$, in addition to $\mathrm{Pt}$ and $\mathrm{Pd}$ ) always leading to the downshift of the metal $d$-band. ${ }^{77}$ In addition, WC substrate was also found to affect the reactivity and segregation trends in $\mathrm{Pd}_{3} \mathrm{Au}$ alloy thin films on $\mathrm{WC}(0001)$ due to the lattice mismatch and strong interactions with $\mathrm{Pt}$ and $\mathrm{Au}^{104}$

\section{HOW FAR IS THE BULK?}

With clear experimental evidence regarding the effects of the composition of the surface layers on the electrocatalytic performance, ${ }^{89}$ the question is how thin/thick the catalyst films (or shells) actually need to be? A clear border between the bulk and surface is rather hard to pin down, and several studies have demonstrated that many properties of a solid are close to those of the bulk already three layers below the surface. ${ }^{105}$ In contrast to experiment, theoretical approaches make such analysis possible. It has recently been shown that the effects of a substrate on the electronic structure, surface segregation processes, and dissolution are quickly lost as the thickness of the catalyst overlayer increases. ${ }^{76}$ In the mentioned study, the series of $\mathrm{Pd}_{3} \mathrm{M}$ and $\mathrm{Pt}_{3} \mathrm{M}(\mathrm{M}=\mathrm{Cu}, \mathrm{Ag}, \mathrm{Au})$ alloys thin films (from mono- to trilayer) on different substrates (close-packed surfaces of $\mathrm{Pd}, \mathrm{Ag}, \mathrm{Pt}, \mathrm{Au}$, and $\mathrm{WC}$ ) were investigated and the electronic structure, segregation, and dissolution energies were evaluated. The obtained set of results for the overlayers of different thickness was then compared with the results obtained from pure strained alloys. The latter set of data was not explicitly calculated but rather estimated from the strain dependence of a given quantity for pure strained alloys. By comparison of explicitly calculated and estimated data, it was concluded that the most important surface properties of alloy overlayers are not influenced by the substrate already for trilayers (Figure 10). In other words, for trilayers, surface properties and consequently electrocatalytic activity are governed solely by geometric factors due to the lattice mismatch between the substrate and the catalyst overlayer.

Based on the results presented in Figure 10, one can see that some properties actually approach the ones of pure strained alloys very quickly, like $E_{d \text {-band }}$ (Figure $10 \mathrm{C}$ ). While the monolayers are under significant influence of the chemical properties of the substrate, the bilayers already "feel" the substrate to a much lesser extent. As expected, the situation is more complicated in the case of segregation energies, where a significant effect of the substrate exists for bilayers. This is of course understandable, as the segregation energy is affected by the difference in the interactions of the substrate with the element, which segregates to the surface and the elements, which goes to the subsurface layer.

This provides a large simplification regarding the prediction of electrocatalytic behavior of various thin film electrocatalysts (three or more atomic layers) as a large number of relevant quantities can be estimated on the basis of the lattice mismatch between the substrate and catalyst layer, taking into consideration only the strained or compressed catalyst layer. Moreover, as it has been shown, one could also establish a database for different electrocatalysts focusing on the strain dependence of different properties which are of interest for the electrocatalytic performance. For example, knowing the strain dependence of $E_{d \text {-band }}$ segregation and dissolution energies, one can estimate these properties for any strained electrocatalyst surface, assuming that the surface structure of the layer deposited on a substrate is the same as for the pure strained material. In this way, the lattice mismatch between the substrate and the catalyst layer (surface strain) becomes the main factor governing surface properties. In this context, the results of Colic and Bandarenka ${ }^{106}$ should be mentioned. The authors have summarized available literature data on the properties of dealloyed Pt-X ORR electrocatalysts, from single crystals and polycrystalline materials to nanoparticles, whose surface consisted of several layers thick Pt shells. Taking into account only the strain, the authors have suggested that the radius of the solute metal can be used as a simple semiempirical descriptor, statistically connected to the resulting lattice strain. This led to a double volcano curve connecting ORR activity with the radius of solvent atoms. While alloying Pt with elements having a smaller atomic radius than $\mathrm{Pt}$ leads to the expected compressive strain in a Pt-rich surface layer and increase of ORR activity (maximum reached for $\mathrm{Cu}$ ), the dissolution of elements with large atomic radii results in the formation of a distinct Pt skin whose structure is not epitaxial to the corresponding alloy core. ${ }^{107}$ Hence, instead of expected tensile strain (as the lattice constant of $\mathrm{Pt}-\mathrm{X}$ is in this case larger than that of $\mathrm{Pt}$ ), the result is again a compressive strain which results with yet another maximum of catalytic activity (reached for Pt-Y). ${ }^{106}$

\section{EXTENDED SURFACE vs NANOPARTICLE}

Extended model surfaces are crucial for the fundamental understanding of main factors governing electrocatalytic properties. However, to be relevant for the real world applications, one needs to develop nanocatalysts. Moreover, theoretical calculations are, as a rule, performed on extended surfaces, as most of the widely employed DFT codes use periodic boundary conditions (VASP, ${ }^{108,109}$ QuantumESPRESSO, ${ }^{110}$ and other codes). So, the question is whether 

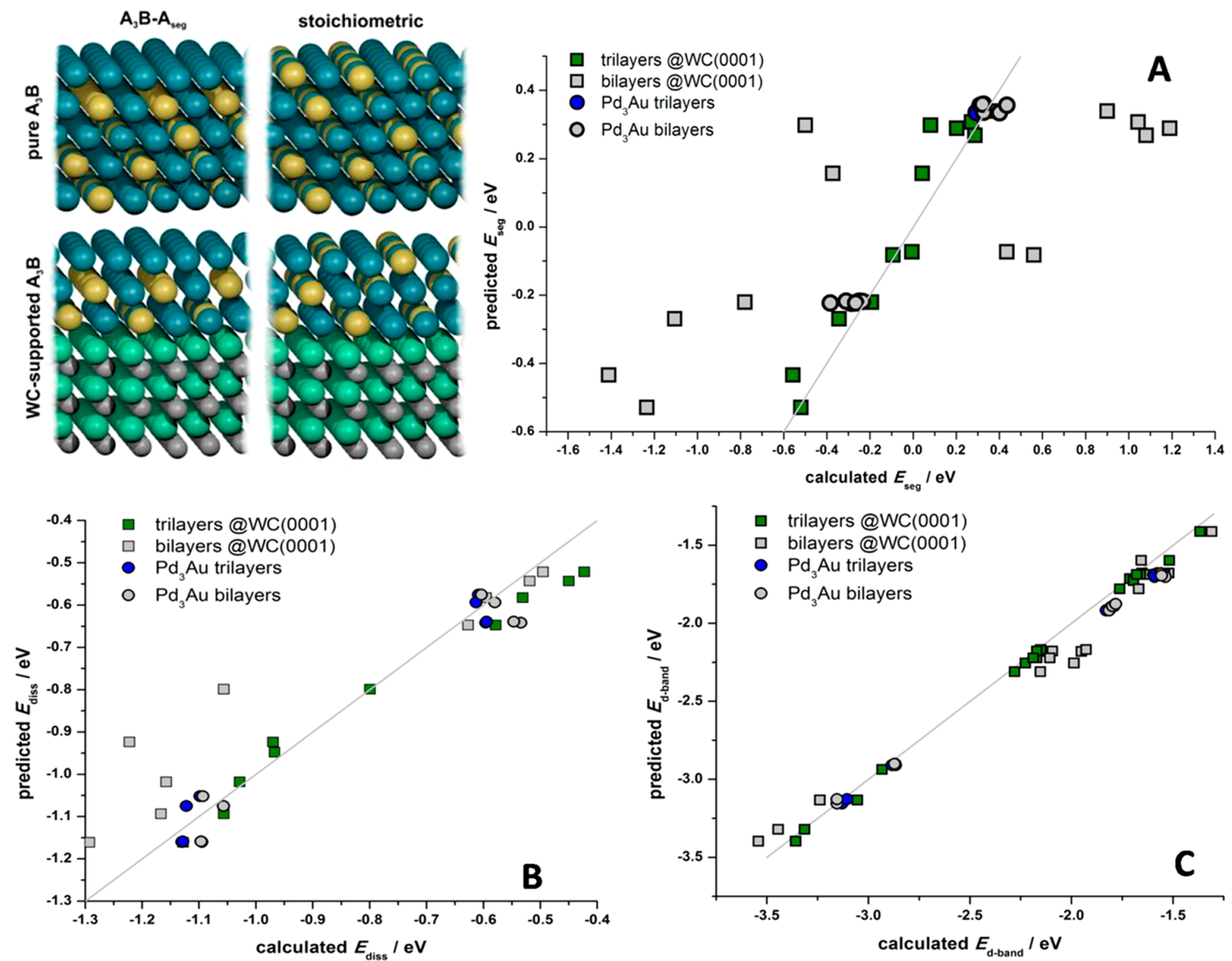

Figure 10. (A) Correlation of the calculated surface segregation energies for the supported bi- and trilayers and the segregation energies predicted on the basis of the strain dependence of $E_{\text {seg }}$ of pure $A_{3} \mathrm{~B}(111)$ surfaces. The gray line represents the $E_{\text {seg }}$ (predicted) $=E_{\text {seg }}$ (calculated) dependence $\left(R^{2}\right.$ (trilayers $\left.)=0.94\right)$. (B) Calculated dissolution energies for the supported bi- and trilayers correlated to the dissolution energies predicted on the basis of the strain dependence for the case of $E_{\text {diss }}$ of pure $A_{3} \mathrm{~B}(111)$ surfaces. The gray line represents the $E_{\text {diss }}$ (predicted) $=E_{\text {diss }}($ calculated) dependence $\left(R^{2}\right.$ (trilayers $\left.)=0.96\right)$. (C) Calculated $d$-band centers for the supported bi- and trilayers correlated to the d-band centers predicted on the basis of the strain dependence of $E_{d \text {-band }}$ of pure $\mathrm{A}_{3} \mathrm{~B}(111)$ surfaces. The gray line represents the $E_{d \text {-band }}$ (predicted) $=E_{d \text {-band }}$ (calculated) dependence $\left(R^{2}\right.$ (trilayers $\left.)=0.998\right) .{ }^{76}$ Reproduced from ref 76 by permission of the PCCP Owner Societies. Copyright 2018.

it is safe to transfer the theoretical results obtained from periodic DFT calculations to design of nanoparticles?

The work on $\mathrm{Pt}_{3} \mathrm{Ni}$ single crystals ${ }^{89}$ has offered a very simple recipe how to make superior nanostructured ORR electrocatalysts: create a nanocatalyst with electronic and morphological properties that mimic those of the $\mathrm{Pt}_{3} \mathrm{Ni}(111)$ surface. Surface segregation processes in the nanoparticle would result in compressive strain of the Pt skin, weaken $\mathrm{OH}_{\text {ads }}$ formation, and enhance the surface availability for ORR. However, the exposed facets of a nanoparticle have to end somewhere, and the question is whether edges could compromise the activity and stability of the nanoparticles. A series of papers on shapeselected Pd nanoparticles with a controllable number of $\mathrm{Pt}$ layers show that the results regarding activity trends obtained by periodic DFT calculations can be transferred to nanoparticles as well. ${ }^{111-113}$ The results regarding the cubic Pd nanoparticles (core) with a controllable number of Pt layers in the shell show a volcano-type dependence of the activity on the number of Pt layers deposited in the shell, which also agrees with the results of DFT calculations almost quantitatively. ${ }^{111}$ Also, it can be observed that for the particles containing six layers of $\mathrm{Pt}$ the activity is very close to that of pure $\mathrm{Pt}$ nanocubes. In the light of the presented results regarding the effect of strain and the thickness of the overlayer/shell, it can be speculated that only a small compressive strain remained operative for thick Pt shells, affecting reactivity in a predictable manner: small compression of Pt lattice increases ORR activity. However, the situation with nanoparticles can be much more complicated in some cases. For example, the work of the same group on palladium-platinum core-shell icosahedra shows that the lateral confinement imposed by twin boundaries allows only for vertical relaxation in the shell that results in corrugated platinum overlayers under compressive strain. ${ }^{113}$ Nevertheless, taking these experimentally observed structural changes into ta heoretical model, it was possible to reproduce the activity trends. One might ask how far from a defect in the nanoparticle the surface does not feel it anymore. The results of Drazic et al. ${ }^{114}$ on twin boundaries in $\mathrm{Cu}_{3} \mathrm{Pt}$ nanoparticles show that composition and lattice changes (i.e., strain) around twin boundaries are attenuated after several atomic layers (three to five) away from the boundary in the lateral direction. This is comparable with the results regarding the effects of the support on the overlayer, showing that the overlayer with three atomic layers feels the substrate to a very low extent. The 
mentioned results show that screening studies performed for extended surfaces, which are almost always perfectly flat, should be transferred to nanoparticles with care. However, the answer to the question presented at the beginning of this section is, generally, yes.

\section{SUMMARY AND OUTLOOK}

In order to provide some final remarks we shall consider first pseudomorphic electrocatalyst layers on foreign substrates.

(i) Monolayered electrocatalysts: Monolayers are under strong influence of the support/core. They are subjected to both strain, which depends on the lattice mismatch between the electrocatalyst and the support/core, and ligand effect. Both effects determine the final electronic structure and the electrocatalytic performance. In monolayers there is no segregation. Possible mixing of the electrocatalytic layer with support/core (partial surface alloying) might not be desirable as a completely new surface is obtained in that case. Dissolution of the monolayer depends on the adhesion to the support/ core. If the adhesion energy is greater than the cohesive energy of bulk catalyst (which is also important for the monolayer formation), it is expected that dissolution will take place at higher potentials compared to pure catalyst. There is a lot of reliable systematic data on monolayers dating even 20 years back $^{57}$ which can be used to predict and understand the properties of monolayer electrocatalysts.

(ii) Bilayer electrocatalysts: Bilayers feel support/core to a much lower extent compared to monolayers. While the strain is the same as in monolayers, its relative contribution to the final electronic structure of a bilayer is much more pronounced than in monolayers. In multimetallic bilayers, surface segregation processes are under strong influence of support/core and depend on the interactionsbetween the support/core and the elements present in the bilayer. Segregation trends can be altered when compared to that when the support/ core is not present. Dissolution of bilayers can be under the influence of the support/core although the surface layer is not in direct contact with it. This effect strongly depends on the nature of substrate/core and takes place both at the solid/vacuum interface and under adsorption conditions on the electrocatalyst surface.

(iii) Trilayers and thicker electrocatalyst layers: In trilayers, the electronic effect of the support/core is basically lost and the only effect of the strain is due to lattice mismatch between the layer and the support. By controlling the strain, one can easily tune surface reactivity and catalytic activity. In multicomponent systems, surface segregation processes take place like in pure strained electrocatalysts. There is a possibility to tune segregation trends by strain engineering, but it appears that there is no general rule for the effect of strain on the segregation valid for a sufficiently large number of systems. ${ }^{76}$ As there are some general guidelines regarding the surface segregation in alloys, ${ }^{66,67}$ the question is whether it would be possible to apply the same logic on strained surfaces, if the strain dependence of surface energies of clean metallic surfaces is known. DFT calculations suggest ${ }^{76}$ that the dissolution of the surface layer of the electrocatalyst is unaffected by the substrate/core, but it is affected by strain. Hence, the use of trilayer catalysts allows one to fully employ the effects of surface strain on the electrocatalytic performance. However, there is not much space to play with, as after five atomic layers the effects of strain also starts to fade. ${ }^{115}$

In the case of nonpseudomorphic catalyst layers, like in some dealloyed surfaces or nanoparticles, it is still possible to consider strain as a driving force which determines the electrocatalytic activity, assuming that the catalyst layer is thick enough. However, it might be more instructive to turn to local architectures and coordination of active sites, , $^{9,106,116}$ which provide adequate electronic structure to boost electrocatalytic activity. Taking Pt-based ORR catalysts as an example, the final result regarding the catalytic activity is the same as for the case of compressive strain, a slight reduction of the surface reactivity which weakens $\mathrm{Pt}-\mathrm{OH}_{\mathrm{ads}}$ bonds and increases the availability of active sites for ORR. In this sense, it might be more appropriate to consider the lengths of local $\mathrm{Pt}-\mathrm{Pt}$ bonds as a measure of strain, following shortlisted guidelines for design of ORR catalysts provided by Xin et al.: ${ }^{\circ}(1)$ creating alloys where the surface $\mathrm{Pt}-\mathrm{Pt}$ bonds are contracted, (2) coordinating Pt surface sites with $3 \mathrm{~d}$ metals, (3) coordinating Pt surface sites with more electronegative metals (such as $\mathrm{Au}$ ).

Finally, we have seen that there is much to be learned from the "bottom-up" approach ${ }^{19}$ of catalyst design, and that DFT provides insights unmatched by any other experimental technique. Still a completely different "top-down" perspective is to be had. As the traditional approach provides ways of lowering the computational $\operatorname{cost}^{76}$ and the community moves away from the practice of keeping the raw computational output exclusive to the authors, the pace of data accumulation could rise to levels too fast to be handled manually. This opens a new opportunity for developing the field, harvesting the vast amounts of data by employing data-mining and machine learning techniques. ${ }^{69,117,118}$ That being said, when employing such methods it is true that more data is always better, but not every data is "good data." The raw output, total energies, of DFT calculations have little value, as only their linear combinations correspond to physical properties that are of interest for catalysis and even slight differences in the computational setup vastly influence the raw output number. That is why extensive care needs to be taken in finding a way of sharing the output (geometries, electronic structure data, energies) while not losing the input information (computational setup), as without the latter, the value of the former is significantly decreased. In spite the complexity of electrified interfaces, which at this moment cannot be fully implemented in theoretical models, these data can be considered as a foundation for building up more complex models and application of other approaches, many of them relying on the input from DFT. Fast and effective means of sharing the data among the community can be accomplished by employing of specialized databases ${ }^{119,120}$ ensuring maximal benefit from the time and energy (counting processor hours and human hours) invested in modeling and computing (electro)catalytic systems. Simple geometrical patterns have been related to (electro)catalytic activity, ${ }^{116}$ and the search for more complex patterns involving geometric, thermodynamic, electronic data (etc.) unlocks the search for hidden behaviors difficult to catch with other methodologies. 


\section{AUTHOR INFORMATION}

\section{Corresponding Author}

*E-mail: igor@ffh.bg.ac.rs. Fax: +381 112187 133. Phone: +381113336625.

ORCID $\odot$

Igor A. Pašti: 0000-0002-1000-9784

Núria López: 0000-0001-9150-5941

\section{Notes}

The authors declare no competing financial interest.

\section{ACKNOWLEDGMENTS}

This work was supported by Serbian Ministry of Education, Science and Technological Development (Project No. III45014) and by the Spanish MINECO (Grant CTQ201568770-R). E.F. thanks MINECO La Caixa Severo Ochoa for a predoctoral grant through Severo Ochoa Excellence Accreditation 20142018 (Grant SEV 2013 0319). N.V.S. acknowledges the support provided by the Swedish Research Council through Project No. 2014-5993. We also acknowledge the support from Carl Tryggers Foundation for Scientific Research (grant no. 17:503), Sweden.

\section{REFERENCES}

(1) Irvine, J. T. S.; Neagu, D.; Verbraeken, M. C.; Chatzichristodoulou, C.; Graves, C.; Mogensen, M. B. Evolution of the Electrochemical Interface in High-Temperature Fuel Cells and Electrolysers. Nat. Energy 2016, 1, 15014.

(2) Sherbo, R. S.; Delima, R. S.; Chiykowski, V. A.; MacLeod, B. P.; Berlinguette, C. P. Complete Electron Economy by Pairing Electrolysis with Hydrogenation. Nat. Catal. 2018, 1, 501-507.

(3) Jacobson, M. Z. Cleaning the Air and Improving Health with Hydrogen Fuel-Cell Vehicles. Science (Washington, DC, U. S.) 2005, 308, 1901-1905.

(4) Kreuer, K. D. On the Development of Proton Conducting Polymer Membranes for Hydrogen and Methanol Fuel Cells. J. Membr. Sci. 2001, 185, 29-39.

(5) Cheng, X.; Shi, Z.; Glass, N.; Zhang, L.; Zhang, J.; Song, D.; Liu, Z. S.; Wang, H.; Shen, J. A Review of PEM Hydrogen Fuel Cell Contamination: Impacts, Mechanisms, and Mitigation. J. Power Sources 2007, 165, 739-756.

(6) de Leon, C. P.; Walsh, F. C.; Pletcher, D.; Browning, D. J.; Lakeman, J. B. Direct Borohydride Fuel Cells. J. Power Sources 2006, $155,172-181$

(7) Simon, P.; Gogotsi, Y.; Dunn, B. Where Do Batteries End and Supercapacitors Begin? Science (Washington, DC, U. S.) 2014, 343, 1210-1211.

(8) Stamenkovic, V. R.; Strmcnik, D.; Lopes, P. P.; Markovic, N. M. Energy and Fuels from Electrochemical Interfaces. Nat. Mater. 2017, $16,57-69$.

(9) Colic, V.; Pohl, M. D.; Scieszka, D.; Bandarenka, A. S. Influence of the Electrolyte Composition on the Activity and Selectivity of Electrocatalytic Centers. Catal. Today 2016, 262, 24-35.

(10) Cheng, T.; Wang, L.; Merinov, B. V.; Goddard, W. A. Explanation of Dramatic PH-Dependence of Hydrogen Binding on Noble Metal Electrode: Greatly Weakened Water Adsorption at High PH. J. Am. Chem. Soc. 2018, 140, 7787-7790.

(11) Gunter, P. L. J.; Niemantsverdriet, J. W.; Ribeiro, F. H.; Somorjai, G. A. Surface Science Approach to Modeling Supported Catalysts. Catal. Rev.: Sci. Eng. 1997, 39, 77-168.

(12) Hammer, B.; Norskov, J. K. Theoretical Surface Science and Catalysis - Calculations and Concepts. Adv. Catal. 2000, 45, 71129.

(13) Nørskov, J. K.; Bligaard, T.; Rossmeisl, J.; Christensen, C. H. Towards the Computational Design of Solid Catalysts. Nat. Chem. 2009, 1, 37-46.
(14) Nørskov, J. K.; Bligaard, T.; Logadottir, A.; Bahn, S.; Hansen, L. B.; Bollinger, M.; Bengaard, H.; Hammer, B.; Sljivancanin, Z.; Mavrikakis, M.; Xu, Y.; Dahl, S.; Jacobsen, C. J. H. Universality in Heterogeneous Catalysis. J. Catal. 2002, 209, 275-278.

(15) Medford, A. J.; Vojvodic, A.; Hummelshøj, J. S.; Voss, J.; AbildPedersen, F.; Studt, F.; Bligaard, T.; Nilsson, A.; Nørskov, J. K. From the Sabatier Principle to a Predictive Theory of Transition-Metal Heterogeneous Catalysis. J. Catal. 2015, 328, 36-42.

(16) García-Muelas, R.; Li, Q.; López, N. Density Functional Theory Comparison of Methanol Decomposition and Reverse Reactions on Metal Surfaces. ACS Catal. 2015, 5, 1027-1036.

(17) Greeley, J.; Jaramillo, T. F.; Bonde, J.; Chorkendorff, I.; Nørskov, J. K. Computational High-Throughput Screening of Electrocatalytic Materials for Hydrogen Evolution. Nat. Mater. 2006, 5, 909-913.

(18) Bampos, G.; Bebelis, S.; Kondarides, D. I.; Verykios, X. Comparison of the Activity of Pd-M ( $\mathrm{M}: \mathrm{Ag}, \mathrm{Co}, \mathrm{Cu}, \mathrm{Fe}, \mathrm{Ni}, \mathrm{Zn}$ ) Bimetallic Electrocatalysts for Oxygen Reduction Reaction. Top. Catal. 2017, 60, 1260-1273.

(19) López, N.; Almora-Barrios, N.; Carchini, G.; Błoński, P.; Bellarosa, L.; García-Muelas, R.; Novell-Leruth, G.; García-Mota, M. State-of-the-Art and Challenges in Theoretical Simulations of Heterogeneous Catalysis at the Microscopic Level. Catal. Sci. Technol. 2012, 2, 2405-2417.

(20) Cao, K.; Cai, J.; Liu, X.; Chen, R. Review Article: Catalysts Design and Synthesis via Selective Atomic Layer Deposition. J. Vac. Sci. Technol., A 2018, 36, 010801.

(21) Kelly, T. G.; Chen, J. G. Metal Overlayer on Metal Carbide Substrate: Unique Bimetallic Properties for Catalysis and Electrocatalysis. Chem. Soc. Rev. 2012, 41, 8021.

(22) Ghosh Chaudhuri, R.; Paria, S. Core/Shell Nanoparticles: Classes, Properties, Synthesis Mechanisms, Characterization, and Applications. Chem. Rev. 2012, 112, 2373-2433.

(23) Mavrikakis, M.; Hammer, B.; Nørskov, J. K. Effect of Strain on the Reactivity of Metal Surfaces. Phys. Rev. Lett. 1998, 81, 2819-2822.

(24) Wang, H.; Xu, S.; Tsai, C.; Li, Y.; Liu, C.; Zhao, J.; Liu, Y.; Yuan, H.; Abild-Pedersen, F.; Prinz, F. B.; Norskov, J. K.; Cui, Y. Direct and Continuous Strain Control of Catalysts with Tunable Battery Electrode Materials. Science (Washington, DC, U. S.) 2016, 354, 1031-1036.

(25) Filhol, J. S.; Saint-Lager, M. C.; De Santis, M.; Dolle, P.; Simon, D.; Baudoing-Savois, R.; Bertolini, J. C.; Sautet, P. Highly Strained Structure of a Four-Layer Deposit of Pd on Ni(110): A Coupled Theoretical and Experimental Study. Phys. Rev. Lett. 2002, 89, 30-33.

(26) Marković, N. M.; Ross, P. N. J. Surface Science Studies of Model Fuel Cell Electrocatalysts. Surf. Sci. Rep. 2002, 45, 117-229.

(27) Trasatti, S. Work Function, Electronegativity, and Electrochemical Behaviour of Metals. III. Electrolytic Hydrogen Evolution in Acid Solutions. J. Electroanal. Chem. Interfacial Electrochem. 1972, 39, 163-184.

(28) Vosko, S. H.; Wilk, L.; Nusair, M. Accurate Spin-Dependent Electron Liquid Correlation Energies for Local Spin Density Calculations: A Critical Analysis. Can. J. Phys. 1980, 58, 1200-1211.

(29) Perdew, J. P.; Burke, K.; Ernzerhof, M. Generalized Gradient Approximation Made Simple. Phys. Rev. Lett. 1996, 77, 3865-3868.

(30) Tao, J.; Perdew, J. P.; Staroverov, V. N.; Scuseria, G. E. Climbing the Density Functional Ladder: Nonempirical Metageneralized Gradient Approximation Designed for Molecules and Solids. Phys. Rev. Lett. 2003, 91, 146401.

(31) Calle-Vallejo, F.; Koper, M. T. M. First-Principles Computational Electrochemistry: Achievements and Challenges. Electrochim. Acta 2012, 84, 3-11.

(32) Nielsen, M.; Björketun, M. E.; Hansen, M. H.; Rossmeisl, J. Towards First Principles Modeling of Electrochemical ElectrodeElectrolyte Interfaces. Surf. Sci. 2015, 631, 2-7.

(33) Eslamibidgoli, M. J.; Huang, J.; Kadyk, T.; Malek, A.; Eikerling, M. How Theory and Simulation Can Drive Fuel Cell Electrocatalysis. Nano Energy 2016, 29, 334-361. 
(34) Rossmeisl, J.; Karlberg, G. S.; Jaramillo, T.; Nørskov, J. K. Steady State Oxygen Reduction and Cyclic Voltammetry. Faraday Discuss. 2009, 140, 337-346.

(35) Viswanathan, V.; Hansen, H. A.; Rossmeisl, J.; Jaramillo, T. F.; Pitsch, H.; Nørskov, J. K. Simulating Linear Sweep Voltammetry from First-Principles: Application to Electrochemical Oxidation of Water on $\mathrm{Pt}(111)$ and Pt3Ni(111). J. Phys. Chem. C 2012, 116, 4698-4704.

(36) Eslamibidgoli, M. J.; Eikerling, M. H. Approaching the SelfConsistency Challenge of Electrocatalysis with Theory and Computation. Curr. Opin. Electrochem. 2018, 9, 189-197.

(37) Nørskov, J. K.; Rossmeisl, J.; Logadottir, A.; Lindqvist, L.; Kitchin, J. R.; Bligaard, T.; Jónsson, H. Origin of the Overpotential for Oxygen Reduction at a Fuel-Cell Cathode. J. Phys. Chem. B 2004, 108, 17886-17892.

(38) Rossmeisl, J.; Skúlason, E.; Björketun, M. E.; Tripkovic, V.; Nørskov, J. K. Modeling the Electrified Solid-liquid Interface. Chem. Phys. Lett. 2008, 466, 68-71.

(39) Tripkovic, V.; Björketun, M. E.; Skúlason, E.; Rossmeisl, J. Standard Hydrogen Electrode and Potential of Zero Charge in Density Functional Calculations. Phys. Rev. B: Condens. Matter Mater. Phys. 2011, 84, 115452.

(40) Tripković, V.; Skúlason, E.; Siahrostami, S.; Nørskov, J. K.; Rossmeisl, J. The Oxygen Reduction Reaction Mechanism on Pt(111) from Density Functional Theory Calculations. Electrochim. Acta 2010, 55, 7975-7981.

(41) Yu, L.; Pan, X.; Cao, X.; Hu, P.; Bao, X. Oxygen Reduction Reaction Mechanism on Nitrogen-Doped Graphene: A Density Functional Theory Study. J. Catal. 2011, 282, 183-190.

(42) Li, Q.; García-Muelas, R.; López, N. Microkinetics of Alcohol Reforming for $\mathrm{H} 2$ Production from a FAIR Density Functional Theory Database. Nat. Commun. 2018, 9, 526.

(43) Garcia-Ratés, M.; García-Muelas, R.; López, N. Solvation Effects on Methanol Decomposition on $\mathrm{Pd}(111), \operatorname{Pt}(111)$, and $\mathrm{Ru}(0001)$. J. Phys. Chem. C 2017, 121, 13803-13809.

(44) Bellarosa, L.; García-Muelas, R.; Revilla-López, G.; López, N. Diversity at the Water-Metal Interface: Metal, Water Thickness, and Confinement Effects. ACS Cent. Sci. 2016, 2, 109-116.

(45) García-Muelas, R.; Dattila, F.; Shinagawa, T.; Martín, A. J.; Pérez-Ramírez, J.; López, N. Origin of the Selective Electroreduction of Carbon Dioxide to Formate by Chalcogen Modified Copper. J. Phys. Chem. Lett. 2018, 9, 7153-7159.

(46) Pašti, I. A.; Leetmaa, M.; Skorodumova, N. V. General Principles for Designing Supported Catalysts for Hydrogen Evolution Reaction Based on Conceptual Kinetic Monte Carlo Modeling. Int. J. Hydrogen Energy 2016, 41, 2526-2538.

(47) Gutić, S. J.; Dobrota, A. S.; Leetmaa, M.; Skorodumova, N. V.; Mentus, S. V.; Pašti, I. A. Improved Catalysts for Hydrogen Evolution Reaction in Alkaline Solutions through the Electrochemical Formation of Nickel-Reduced Graphene Oxide Interface. Phys. Chem. Chem. Phys. 2017, 19, 13281-13293.

(48) Wang, X.; Lau, K. C.; Turner, C. H.; Dunlap, B. I. Kinetic Monte Carlo Simulation of the Elementary Electrochemistry in a Hydrogen-Powered Solid Oxide Fuel Cell. J. Power Sources 2010, 195, 4177-4184.

(49) Reuter, K.; Scheffler, M. First-Principles Kinetic Monte Carlo Simulations for Heterogeneous Catalysis: Application to the $\mathrm{CO}$ Oxidation at RuO2 (110). Phys. Rev. B: Condens. Matter Mater. Phys. 2006, 73, 045433 .

(50) Mace, A.; Leetmaa, M.; Laaksonen, A. Temporal Coarse Graining of CO2 and N2 Diffusion in Zeolite NaKA: From the Quantum Scale to the Macroscopic. J. Chem. Theory Comput. 2015, 11, 4850-4860.

(51) Gawande, M. B.; Goswami, A.; Asefa, T.; Guo, H.; Biradar, A. V.; Peng, D.-L.; Zboril, R.; Varma, R. S. Core-shell Nanoparticles: Synthesis and Applications in Catalysis and Electrocatalysis. Chem. Soc. Rev. 2015, 44, 7540-7590.

(52) Yang, Y.; Chen, C.-C.; Scott, M. C.; Ophus, C.; Xu, R.; Pryor, A.; Wu, L.; Sun, F.; Theis, W.; Zhou, J.; Eisenbach, M.; Kent, P. R. C.; Sabirianov, R. F.; Zeng, H.; Ercius, P.; Miao, J. Deciphering Chemical
Order/Disorder and Material Properties at the Single-Atom Level. Nature 2017, 542, 75-79.

(53) Almora-Barrios, N.; Cano, I.; Van Leeuwen, P. W. N. M.; López, N. Concerted Chemoselective Hydrogenation of Acrolein on Secondary Phosphine Oxide Decorated Gold Nanoparticles. ACS Catal. 2017, 7, 3949-3954.

(54) Almora-Barrios, N.; Vilé, G.; Garcia-Ratés, M.; Pérez-Ramírez, J.; López, N. Electrochemical Effects at Surfactant-Platinum Nanoparticle Interfaces Boost Catalytic Performance. ChemCatChem 2017, 9, 604-609.

(55) Hammer, B.; Norskov, J. K. Why Gold Is the Noblest of All the Metals. Nature 1995, 376, 238-240.

(56) Hammer, B.; Nørskov, J. K. Electronic Factors Determining the Reactivity of Metal Surfaces. Surf. Sci. 1995, 343, 211-220.

(57) Ruban, A.; Hammer, B.; Stoltze, P.; Skriver, H. L.; Nørskov, J. K. Surface Electronic Structure and Reactivity of Transition and Noble Metals. J. Mol. Catal. A: Chem. 1997, 115, 421-429.

(58) Pettersson, L. G. M.; Nilsson, A. A Molecular Perspective on the D-Band Model: Synergy Between Experiment and Theory. Top. Catal. 2014, 57, 2-13.

(59) Xin, H.; Vojvodic, A.; Voss, J.; Nørskov, J. K.; Abild-Pedersen, F. Effects of d -Band Shape on the Surface Reactivity of TransitionMetal Alloys. Phys. Rev. B: Condens. Matter Mater. Phys. 2014, 89, 15 .

(60) Silva, T. A. G.; Teixeira-Neto, E.; López, N.; Rossi, L. M. Volcano-like Behavior of Au-Pd Core-Shell Nanoparticles in the Selective Oxidation of Alcohols. Sci. Rep. 2015, 4, 1-5.

(61) Xin, H.; Holewinski, A.; Linic, S. Predictive Structurereactivity Models for Rapid Screening of Pt-Based Multimetallic Electrocatalysts for the Oxygen Reduction Reaction. ACS Catal. 2012, 2, 12-16.

(62) Fako, E.; Łodziana, Z.; López, N. Comparative Single Atom Heterogeneous Catalysts (SAHCs) on Different Platforms: A Theoretical Approach. Catal. Sci. Technol. 2017, 7, 4285-4293.

(63) Greiner, M. T.; Jones, T. E.; Beeg, S.; Zwiener, L.; Scherzer, M.; Girgsdies, F.; Piccinin, S.; Armbrüster, M.; Knop-Gericke, A.; Schlögl, R. Free-Atom-like d States in Single-Atom Alloy Catalysts. Nat. Chem. 2018, 10, 1008-1015.

(64) Papp, C. Catalysis at the Limit. Nat. Chem. 2018, 10, 995-996.

(65) Walsh, A.; Sokol, A. A.; Buckeridge, J.; Scanlon, D. O.; Catlow, C. R. A. Oxidation States and Ionicity. Nat. Mater. 2018, 17, 958964.

(66) Ruban, A. V.; Skriver, H. L.; Nørskov, J. K. Surface Segregation Energies in Transition-Metal Alloys. Phys. Rev. B: Condens. Matter Mater. Phys. 1999, 59, 15990-16000.

(67) Ruban, A. V.; Skriver, H. L. Calculated Surface Segregation in Transition Metal Alloys. Comput. Mater. Sci. 1999, 15, 119-143.

(68) Vitos, L.; Ruban, A. V.; Skriver, H. L.; Kollár, J. The Surface Energy of Metals. Surf. Sci. 1998, 411, 186-202.

(69) Medford, A. J.; Kunz, M. R.; Ewing, S. M.; Borders, T.; Fushimi, R. Extracting Knowledge from Data through Catalysis Informatics. ACS Catal. 2018, 8, 7403-7429.

(70) Ma, Y.; Balbuena, P. B. Pt Surface Segregation in Bimetallic Pt3M Alloys: A Density Functional Theory Study. Surf. Sci. 2008, 602, 107-113.

(71) Ma, Y.; Balbuena, P. B. Surface Segregation in Bimetallic Pt3M $(\mathrm{M}=\mathrm{Fe}, \mathrm{Co}, \mathrm{Ni})$ Alloys with Adsorbed Oxygen. Surf. Sci. 2009, 603, 349-353.

(72) Sasaki, K.; Shao, M.; Adzic, R. Dissolution and Stabilization of Platinum in Oxygen Cathodes. In Polymer Electrolyte Fuel Cell Durability; Springer New: New York, 2009; pp 7-27.

(73) Zhang, J.; Sasaki, K.; Sutter, E.; Adzic, R. R. Stabilization of Platinum Oxygen-Reduction Electrocatalysts Using Gold Clusters. Science (Washington, DC, U. S.) 2007, 315, 220-222.

(74) Jovanovič, P.; Pavlišič, A.; Šlih, V. S.; Šala, M.; Hodnik, N.; Bele, M.; Hočevar, S.; Gaberšček, M. New Insight into Platinum Dissolution from Nanoparticulate Platinum-Based Electrocatalysts Using Highly Sensitive in Situ Concentration Measurements. Chem CatChem 2014, 6, 449-453. 
(75) Hodnik, N.; Dehm, G.; Mayrhofer, K. J. J. Importance and Challenges of Electrochemical in Situ Liquid Cell Electron Microscopy for Energy Conversion Research. Acc. Chem. Res. 2016, 49, 2015-2022.

(76) Fako, E.; Dobrota, A. S.; Pašti, I. A.; López, N.; Mentus, S. V.; Skorodumova, N. V. Lattice Mismatch as the Descriptor of Segregation, Stability and Reactivity of Supported Thin Catalyst Films. Phys. Chem. Chem. Phys. 2018, 20, 1524-1530.

(77) Vasić Anićijević, D. D.; Nikolić, V. M.; Marčeta-Kaninski, M. P.; Pašti, I. A. Is Platinum Necessary for Efficient Hydrogen Evolution? - DFT Study of Metal Monolayers on Tungsten Carbide. Int. J. Hydrogen Energy 2013, 38, 16071-16079.

(78) Hawkins, J. M.; Weaver, J. F.; Asthagiri, A. Density Functional Theory Study of the Initial Oxidation of the Pt(111) Surface. Phys. Rev. B: Condens. Matter Mater. Phys. 2009, 79, 125434.

(79) Eslamibidgoli, M. J.; Eikerling, M. H. Atomistic Mechanism of Pt Extraction at Oxidized Surfaces: Insights from DFT. Electrocatalysis 2016, 7, 345-354

(80) Brankovic, S. R.; Wang, J. X.; Adžic', R. R. Pt Submonolayers on Ru Nanoparticles: A Novel Low Pt Loading, High CO Tolerance Fuel Cell Electrocatalyst. Electrochem. Solid-State Lett. 2001, 4, A217.

(81) Brankovic, S. R.; Wang, J. X.; Adžić, R. R. Metal Monolayer Deposition by Replacement of Metal Adlayers on Electrode Surfaces. Surf. Sci. 2001, 474, L173-L179.

(82) Zhang, J.; Mo, Y.; Vukmirovic, M. B.; Klie, R.; Sasaki, K.; Adzic, R. R. Platinum Monolayer Electrocatalysts for $\mathrm{O}{ }_{2}$ Reduction: $\mathrm{Pt}$ Monolayer on $\mathrm{Pd}(111)$ and on Carbon-Supported Pd Nanoparticles. J. Phys. Chem. B 2004, 108, 10955-10964.

(83) Zhang, J.; Vukmirovic, M. B.; Xu, Y.; Mavrikakis, M.; Adzic, R. R. Controlling the Catalytic Activity of Platinum-Monolayer Electrocatalysts for Oxygen Reduction with Different Substrates. Angew. Chem., Int. Ed. 2005, 44, 2132-2135.

(84) Paulus, U. A.; Wokaun, A.; Scherer, G. G.; Schmidt, T. J.; Stamenkovic, V.; Radmilovic, V.; Markovic, N. M.; Ross, P. N Oxygen Reduction on Carbon-Supported Pt-Ni and Pt-Co Alloy Catalysts. J. Phys. Chem. B 2002, 106, 4181-4191.

(85) Stamenković, V.; Schmidt, T. J.; Ross, P. N.; Marković, N. M. Surface Composition Effects in Electrocatalysis: Kinetics of Oxygen Reduction on Well-Defined Pt3Ni and Pt3Co Alloy Surfaces. J. Phys. Chem. B 2002, 106, 11970-11979.

(86) Stamenković, V.; Schmidt, T. J.; Ross, P. N.; Marković, N. M. Surface Segregation Effects in Electrocatalysis: Kinetics of Oxygen Reduction Reaction on Polycrystalline Pt3Ni Alloy Surfaces. J. Electroanal. Chem. 2003, 554-555, 191-199.

(87) Stamenkovic, V.; Mun, B. S.; Mayrhofer, K. J. J.; Ross, P. N.; Markovic, N. M.; Rossmeisl, J.; Greeley, J.; Nørskov, J. K. Changing the Activity of Electrocatalysts for Oxygen Reduction by Tuning the Surface Electronic Structure. Angew. Chem., Int. Ed. 2006, 45, 28972901.

(88) Stamenkovic, V. R.; Mun, B. S.; Arenz, M.; Mayrhofer, K. J. J.; Lucas, C. A.; Wang, G.; Ross, P. N.; Markovic, N. M. Trends in Electrocatalysis on Extended and Nanoscale Pt-Bimetallic Alloy Surfaces. Nat. Mater. 2007, 6, 241-247.

(89) Stamenkovic, V. R.; Fowler, B.; Mun, B. S.; Wang, G.; Ross, P. N.; Lucas, C. A.; Markovic, N. M. Improved Oxygen Reduction Activity on Pt3Ni(111) via Increased Surface Site Availability. Science (Washington, DC, U. S.) 2007, 315, 493-497.

(90) Mani, P.; Srivastava, R.; Strasser, P. Dealloyed Pt - Cu Core Shell Nanoparticle Electrocatalysts for Use in PEM Fuel Cell Cathodes. J. Phys. Chem. C 2008, 112, 2770-2778.

(91) Strasser, P.; Koh, S.; Anniyev, T.; Greeley, J.; More, K.; Yu, C.; Liu, Z.; Kaya, S.; Nordlund, D.; Ogasawara, H.; Toney, M. F.; Nilsson, A. Lattice-Strain Control of the Activity in Dealloyed CoreShell Fuel Cell Catalysts. Nat. Chem. 2010, 2, 454-460.

(92) Tymoczko, J.; Calle-Vallejo, F.; Čolić, V.; Schuhmann, W.; Bandarenka, A. S. Evaluation of the Electrochemical Stability of Model Cu-Pt(111) Near-Surface Alloy Catalysts. Electrochim. Acta 2015, 179, 469-474.
(93) Wang, D.; Xin, H. L.; Hovden, R.; Wang, H.; Yu, Y.; Muller, D. A.; Disalvo, F. J.; Abruña, H. D. Structurally Ordered Intermetallic Platinum-Cobalt Core-Shell Nanoparticles with Enhanced Activity and Stability as Oxygen Reduction Electrocatalysts. Nat. Mater. 2013, $12,81-87$.

(94) Sheng, W.; Gasteiger, H. A.; Shao-Horn, Y. Hydrogen Oxidation and Evolution Reaction Kinetics on Platinum: Acid vs Alkaline Electrolytes. J. Electrochem. Soc. 2010, 157, B1529-B1536.

(95) Yan, K.; Maark, T. A.; Khorshidi, A.; Sethuraman, V. A.; Peterson, A. A.; Guduru, P. R. The Influence of Elastic Strain on Catalytic Activity in the Hydrogen Evolution Reaction. Angew. Chem., Int. Ed. 2016, 55, 6175-6181.

(96) Pašti, I. A.; Gavrilov, N. M.; Mentus, S. V. Hydrogen Adsorption on Palladium and Platinum Overlayers: DFT Study. Adv. Phys. Chem. 2011, 2011, 305634.

(97) Temmel, S. E.; Fabbri, E.; Pergolesi, D.; Lippert, T.; Schmidt, T. J. Investigating the Role of Strain toward the Oxygen Reduction Activity on Model Thin Film Pt Catalysts. ACS Catal. 2016, 6, 75667576.

(98) Levy, R. B.; Boudart, M. Platinum-like Behavior of Tungsten Carbide in Surface Catalysis. Science (Washington, DC, U. S.) 1973, $181,547-549$

(99) Esposito, D. V.; Hunt, S. T.; Stottlemyer, A. L.; Dobson, K. D.; McCandless, B. E.; Birkmire, R. W.; Chen, J. G. Low-Cost HydrogenEvolution Catalysts Based on Monolayer Platinum on Tungsten Monocarbide Substrates. Angew. Chem., Int. Ed. 2010, 49, 9859-9862.

(100) Esposito, D. V.; Chen, J. G. Monolayer Platinum Supported on Tungsten Carbides as Low-Cost Electrocatalysts: Opportunities and Limitations. Energy Environ. Sci. 2011, 4, 3900-3912.

(101) Esposito, D. V.; Hunt, S. T.; Kimmel, Y. C.; Chen, J. G. A New Class of Electrocatalysts for Hydrogen Production from Water Electrolysis: Metal Monolayers Supported on Low-Cost Transition Metal Carbides. J. Am. Chem. Soc. 2012, 134, 3025-3033.

(102) Liu, Y.; Mustain, W. E. Evaluation of Tungsten Carbide as the Electrocatalyst Support for Platinum Hydrogen Evolution/Oxidation Catalysts. Int. J. Hydrogen Energy 2012, 37, 8929-8938.

(103) Vasić, D. D.; Pašti, I. A.; Mentus, S. V. DFT Study of Platinum and Palladium Overlayers on Tungsten Carbide: Structure and Electrocatalytic Activity toward Hydrogen Oxidation/Evolution Reaction. Int. J. Hydrogen Energy 2013, 38, 5009-5018.

(104) Vasić Anićijević, D. D.; Nikolić, V. M.; Marčeta Kaninski, M. P.; Pašti, I. A. Structure, Chemisorption Properties and Electrocatalysis by Pd3Au Overlayers on Tungsten Carbide - A DFT Study. Int. J. Hydrogen Energy 2015, 40, 6085-6096.

(105) Roudgar, A.; Groß, A. Local Reactivity of Metal Overlayers: Density Functional Theory Calculations of Pd on Au. Phys. Rev. B: Condens. Matter Mater. Phys. 2003, 67, 033409.

(106) Colić, V.; Bandarenka, A. S. Pt Alloy Electrocatalysts for the Oxygen Reduction Reaction: From Model Surfaces to Nanostructured Systems. ACS Catal. 2016, 6, 5378-5385.

(107) Escudero-Escribano, M.; Malacrida, P.; Hansen, H. M.; VejHansen, U.; Velazquez-Palenzuela, A.; Tripkovic, V.; Schiøtz, J.; Rossmeisl, J.; Stephens, I. E. L.; Chorkendorff, I. Dering That Can Enable the Engineering of Material Properties Through Spontaneous Ordering of Nanoparticles. Science (Washington, DC, U. S.) 2016, 352, $73-76$.

(108) Kresse, G.; Furthmüller, J. Efficient Iterative Schemes for Ab Initio Total-Energy Calculations Using a Plane-Wave Basis Set. Phys. Rev. B: Condens. Matter Mater. Phys. 1996, 54, 11169-11186.

(109) Kresse, G.; Furthmüller, J. Efficiency of Ab Initio Total Energy Calculations for Metals and Semiconductors Using a Plane Wave Basis Set. Comput. Mater. Sci. 1996, 6, 15 .

(110) Giannozzi, P.; Baroni, S.; Bonini, N.; Calandra, M.; Car, R.; Cavazzoni, C.; Ceresoli, D.; Chiarotti, G. L.; Cococcioni, M.; Dabo, I.; Dal Corso, A.; de Gironcoli, S.; Fabris, S.; Fratesi, G.; Gebauer, R.; Gerstmann, U.; Gougoussis, C.; Kokalj, A.; Lazzeri, M.; MartinSamos, L.; Marzari, N.; Mauri, F.; Mazzarello, R.; Paolini, S.; Pasquarello, A.; Paulatto, L.; Sbraccia, C.; Scandolo, S.; Sclauzero, G.; Seitsonen, A. P.; Smogunov, A.; Umari, P.; Wentzcovitch, R. M. 
QUANTUM ESPRESSO: A Modular and Open-Source Software Project for Quantum Simulations of Materials. J. Phys.: Condens. Matter 2009, 21, 395502.

(111) Xie, S.; Choi, S.-I.; Lu, N.; Roling, L. T.; Herron, J. A.; Zhang, L.; Park, J.; Wang, J.; Kim, M. J.; Xie, Z.; Mavrikakis, M.; Xia, Y. Atomic Layer-by-Layer Deposition of $\mathrm{Pt}$ on $\mathrm{Pd}$ Nanocubes for Catalysts with Enhanced Activity and Durability toward Oxygen Reduction. Nano Lett. 2014, 14, 3570-3576.

(112) Park, J.; Zhang, L.; Choi, S.-I.; Roling, L. T.; Lu, N.; Herron, J. A.; Xie, S.; Wang, J.; Kim, M. J.; Mavrikakis, M.; Xia, Y. Atomic Layerby-Layer Deposition of Platinum on Palladium Octahedra for Enhanced Catalysts toward the Oxygen Reduction Reaction. ACS Nano 2015, 9, 2635-2647.

(113) Wang, X.; Choi, S.-I.; Roling, L. T.; Luo, M.; Ma, C.; Zhang, L.; Chi, M.; Liu, J.; Xie, Z.; Herron, J. A.; Mavrikakis, M.; Xia, Y. Palladium-platinum Core-Shell Icosahedra with Substantially Enhanced Activity and Durability towards Oxygen Reduction. Nat. Commun. 2015, 6, 7594

(114) Drazic, G.; Zepeda, F. R.; Lautar, A.; Jovanovic, P.; Bele, M.; Gaberscek, M. Quantitative Approach to Twin Boundaries in Cu3Pt Nanoparticles. In European Microscopy Congress 2016: Proceedings; Wiley-VCH Verlag GmbH \& Co. KGaA: Weinheim, Germany, 2016; Vol. 12, pp 904-905.

(115) Schlapka, A.; Lischka, M.; Groß, A.; Käsberger, U.; Jakob, P. Surface Strain versus Substrate Interaction in Heteroepitaxial Metal Layers: Pt on $\mathrm{Ru}(0001)$. Phys. Rev. Lett. 2003, 91, 016101.

(116) Calle-Vallejo, F.; Tymoczko, J.; Colic, V.; Vu, Q. H.; Pohl, M. D.; Morgenstern, K.; Loffreda, D.; Sautet, P.; Schuhmann, W.; Bandarenka, A. S. Finding Optimal Surface Sites on Heterogeneous Catalysts by Counting Nearest Neighbors. Science (Washington, DC, U. S.) 2015, 350, 185-189.

(117) Kitchin, J. R. Machine Learning in Catalysis. Nat. Catal. 2018, 1, 230-232.

(118) Goldsmith, B. R.; Esterhuizen, J.; Liu, J.-X.; Bartel, C. J.; Sutton, C. Machine Learning for Heterogeneous Catalyst Design and Discovery. AIChE J. 2018, 64, 2311-2323.

(119) Bo, C.; Maseras, F.; López, N. The Role of Computational Results Databases in Accelerating the Discovery of Catalysts. Nat. Catal. 2018, 1, 809-810.

(120) Álvarez-Moreno, M.; De Graaf, C.; López, N.; Maseras, F.; Poblet, J. M.; Bo, C. Managing the Computational Chemistry Big Data Problem: The IoChem-BD Platform. J. Chem. Inf. Model. 2015, 55, 95-103. 